Article

\title{
Harnessing Sustainable Motivation: A Grounded Theory Exploration of Public Service Motivation in Local Governments of the State of Oregon, United States
}

\author{
Sajjad Haider ${ }^{1,2, *(D)}$, Guoxian Bao ${ }^{1, *}$, Gary L. Larsen ${ }^{3}$ and Muhammad Umar Draz ${ }^{4}$ \\ 1 School of Management, Lanzhou University, Lanzhou 730000, China \\ 2 Department of Business Management, Karakoram International University, Gilgit-Baltistan 15100, Pakistan \\ 3 Hatfield School of Government, Portland State University, Portland, OR 97207, USA; glarsen@pdx.edu \\ 4 Department of Management and Humanities, Universiti Teknologi PETRONAS, Seri Iskandar 32610, \\ Malaysia; umar.draz@utp.edu.my \\ * Correspondence: sajjad.hrm@gmail.com or sajjad.haider@kiu.edu.pk (S.H.); baogx@lzu.edu.cn (G.B.); \\ Tel.: +86-15002630944 (S.H.)
}

Received: 17 May 2019; Accepted: 22 May 2019; Published: 1 June 2019

\begin{abstract}
Employee motivation has always been a matter of concern for both public and private sector organizations. Since the industrial revolution in the late 18th century, organizations have struggled to foster workforce motivation and morale to enhance productivity. While a plethora of literature focuses on private sector motivation research, public sector organizations receive only modest scholarly attention. However, a new concept has emerged in public management literature during the late 1980s and 1990s, later known as public service motivation (PSM). The debate about PSM is premised on the notion that the motivation of public sector employees is quite different from their private sector counterparts because of their orientation to public service. Perry and Wise (1990) expressed this concept in the theory of PSM. Subsequently, a growing stream of scholarship has emerged which explores the many aspects of antecedents and outcomes related to PSM. However, questions remain about how to best keep the motivation of public sector employees sustainably high, and about what factors embolden or enervate the motivation and morale of public sector employees. This study focuses on the sustainable work motivation of local government employees. Its arguments and discussions draw from PSM theory, total quality management (TQM) principles, and inspiration from Sustainable Development Goals (SDGs). This study examines and attempts to uncover the career trajectories of local government employees in the State of Oregon, United States, through a rigorous grounded theory method (GTM) of inquiry. The study reveals a number of factors that facilitate and/or inhibit employees' PSM. We expect the findings to be useful for both practitioners and government human resource policymakers in understanding the subtlety and vicissitudes of public sector employee careers and motivations.
\end{abstract}

Keywords: sustainable motivation; public service motivation; total quality management; grounded theory method; local government

\section{Introduction}

Governance has always been acknowledged as an essential, but largely implicit, aspect of sustainable development. Starting with the inception of sustainable development in "Our Common Future", the World Commission on Environment and Development (WCED) recognized the importance of national policies and institutions in choosing policy paths to sustainability (pp. 313-314) [1]. More 
recently, Güney [2] stated that studies from 121 countries show a positive correlation between the level of governance and the level of sustainable development; the author found government effectiveness as the most significant factor among the six factors considered for evaluating governance [2]. In turn, Petrovsky and Ritz [3] observed that a growing body of literature has indicated the importance of public service motivation (PSM).

The effectiveness of public sector governance has been recognized as one of the pillars of development and prosperity. Given its significance, the UN Global Forum on Reinventing Government [4] declared it as a top agenda in United Nations' Programme of Reinventing Government under the aegis of Millennium Development Goals (MDGs). Adopted by UN General Assembly in 2000, the MDGs are eight measurable goals and guidelines with an overarching aim of eradicating poverty, promoting education, combating epidemics, and bringing prosperity in the world, especially focusing on underdeveloped countries. Taking government performance, efficiency, and good governance as priority areas, the UN has urged its member countries to improve their governance and delivery of services to citizens. Without question, the realization of the MDGs requires a trained and skilled workforce, improved governance, inclusive policies, and the forging of partnerships with stakeholders (p. 18) [4]. To this end, the sustained high morale and motivation of the public sector workforce is a key factor for achieving the MDGs and Sustainable Development Goals (SDGs).

More broadly, despite the extended scope of functions and size of government, public sector organizations around the world are confronted with the challenge of improving efficiency and effectiveness, in order to provide better services to citizens. Material resources are often limited, and human resources often lack training or motivation in striving to achieve organizational goals. To face these challenges, governments have turned to a variety of evolving public administration philosophies, including pre-classic nation building, classical public administration (PA), new public management (NPM), new public governance (NPG), and public value-based performance governance (PVG; p. 456) [5]. In addition, organizations have tried various management and leadership approaches, including the total quality management (TQM) philosophies of Kaizen and its associated continuous improvement (CI) as a means of enhancing the motivation and morale of employees, as well as addressing the issues of declining performance and diminishing motivation of public sector employees [6]. This current study offers an understanding of how to harness sustainable public service motivation as a critical factor in achieving these challenges that government organizations face.

As a closing to this introduction, honoring the logical rigor of criteria for measuring sustainable development, it is worth spending a moment to focus on the units of analysis. The primary units of analysis of this study are individual public service employees and their motivations, which can ultimately lead to improved or diminished organizational performance and government performance. The primary units of analysis for governments in deploying their public organizations for public purposes are the philosophies of public administration, articulated briefly above, under which public organizations are organized and led, which can also lead to improved or diminished organizational performance in the name of governance. The primary units of analysis for TQM are organizations, and the processes they employ to organize and deploy organizational resources in the achievement of high organizational performance. All three of these approaches share a common ultimate goal of improved organizational leadership for improved governance. While the three approaches are aimed at similar ultimate outcomes, they are each unique in their units of analysis and resulting implications for leadership and management of organizations and governance.

During the last four decades, scholars in the field of management and organizational behavior have attempted to explore the dynamics of public workforce motivation and the factors that attract employees to serve in public sector organizations. Early scholars of public management, such as Buchanan [7] and Rainey [8], have pointed out this crucial gap in employee management and called for more robust studies on exploring how to unleash employee motivation in public sector organizations. Buchanan [7] in his seminal study used the term "public service ethic" to distinguish the public service and motivational characteristic of public and private sector employees. Perry and Wise's theory of public 
service motivation [9], and later, Perry's measurement tool of PSM [10] provided, however, the impetus for a robust stream of scholarship on public management and early scholars including, but not limited to, Naff and Crum [11], Alonso and Lewis [12], Brewer and Selden [13], Brewer, Ritz, and Vandenabeele [14], and Kim et al. [15], who explored various antecedents, outcomes, and nuances of PSM. As a result, a new stream of research in public management came to prominence in the 1990s, resulting in public service motivation (PSM) being now recognized as a significant theory explaining why those working for the public sector have higher levels of motivation than their counterparts in other sectors [9].

Myriads of studies on PSM have consistently shown that individuals with high PSM are more likely to perform better in their jobs [11,12,16-18]. However, the question of how to sustain and keep motivation and PSM consistently high seems only sparingly answered in the existing literature on public sector work motivation. Moreover, the sustainability literature gives only modest attention to employee motivation, and is more focused on process improvement (PI) and continuous improvement (CI) using the TQM tools such as Lean/Kaizen, Six Sigma, 5S, etc. The role, however, of employees as the agents of bringing change in $C I$ and PI programs has not been fully explored in academic literature.

This study explores employee motivation and public service motivation (PSM) in local governments in the state of Oregon, United States, and how TQM principles and philosophies might help in harnessing and instituting sustainable motivation. The findings of this study will make an important contribution to the existing body of literature on employee motivation regarding the use of TQM principles to bringing efficiency and sustained high motivation. Generally, Kaizen, Lean and CI are ascribed to process improvement in the manufacturing sector, however, its usefulness as a means of boosting employee motivation and morale has had little exploration. In the later sections, we will give a snapshot of the applicability of TQM to the public sector by highlighting some examples of the public organizations that have successfully implemented it. The findings of this study will be useful to practitioners and personnel policymakers in government, to better understand the career trajectories of public sector employees and the internal and external elements that facilitate and inhibit motivation of employees in local governments.

\section{Theoretical Framework}

\subsection{Reality Shock as a Predictor of Declining Motivation}

The attraction-selection-attrition (ASA) model postulated by Schneider [19] and person-environment fit (P-E fit) [20] explains that if individuals' psychological dispositions and environmental characteristics matches, then individuals tend to stay in a job. Taking into account this notion, individuals charged with the spirit of serving public interest opt for public sector careers (see Schott, Steen, and Van Kleef) [21]. While a number of studies indicate a positive relation between public sector employment and PSM [18,22,23], Kjeldsen and Jacobsen found, however, that PSM is irrelevant for attraction to public sector and sector choice; rather, PSM tends to be severely impinged after entry to the public sector (p. 899) [24]. Similarly, Yung [25] came to the conclusion that PSM is not the major reason for individuals' joining the public sector, rather individuals are motivated by self-interest, such as job security and fringe benefits in the public sector (p. 436). This phenomenon has been better explained by rational choice theory and public choice theory, which postulate that like other human beings, public sector officials and bureaucrats could be motivated by the self-interest of maximizing their own benefit, and may have the intention of gaining power and prestige instead of serving citizens and the nation $[25,26]$.

The public sector grapples with the perennial issue of the declining motivation of its workforce as a result of a number of internal organizational factors (such as incongruent organizational culture and unsupportive personnel policies and practices) and external factors (such as economic uncertainty, budgetary constraints in the wake of austerity measures adopted by many governments across the globe, limited extrinsic rewards, and the wearing out of intrinsic motives, to name just a few). Although public sector organizations boast strong intrinsic motives on the part of employees, the influence of 
intrinsic motives fade away over time as serving in the public becomes taken for granted by individuals working in the same sector for years.

New employees from younger generations often join public service with high expectations and idealized views of public organizations being ideal organizations with smooth and highly effective workplaces-an ideal rarely attained in the real world. In reality, public organizations are composed of heterogeneous individuals of different backgrounds, cultures, classes, and dispositions [27-29] and the work processes are not as smooth and efficient as we might hope or surmise from textbooks on organizational management and leadership. When individuals confront this situation, especially for people joining the public sector for the first time, their high expectations and image of a vibrant workplace dwindles. This can dampen motivation and morale of public sector employees when faced with the procedural complexities, red tape $[25,30,31]$ and unexpected public sector working style, and organizational culture in the public sector. This can trigger disillusionment and declining interest on the part of public sector employees [24] as they follow in the suit of going slow and achieving only a lackluster performance, which is often ascribed to the public sector organizational culture.

This phenomenon can be well-explained as "reality shock" [24,32]. The term "reality shock" was first coined by Hughes [33], and later received modest attention from scholars of public management. Some scholars ascribe "reality shock" as a major cause of the declining motivation of public sector employees [24,34]. This reality shock for newcomers is primarily attributed to the lack of clear understanding and familiarity with the nature of work in the public sector [21]. Individuals lacking coping strategies seem to be more affected by the negative consequences of reality shock, whereas some other individuals having the ability and endurance to bear the shocks are lesser affected by the unmet expectations and discouraging elements of the job [21]. With the exception of some progressive public sector organizations, a comprehensive and objective orientation and socialization plan for newcomers is generally missing in the public sector, as it is deemed to be of lesser importance than the bigger issues confronted by the public sector. To this end, public sector human resources has an important role to play in orienting and making sure that newcomers and younger employees get a realistic perspective of the work processes and organizational culture, and still infuse their spirit of public service.

Red tape and bureaucracy are a major source of demotivation for internal customers (employees) [21,24,30,35], while for external customers (citizens), it is the main cause of the prejudiced image of the public sector being slow and bureaucratic. Scott and Pandey argue, however, that managers having a high level of PSM are less likely to perceive red tape (p. 155) [36] and, hence, may be less affected by its negative influence.

Although public sector employees have a higher desire and intention of contributing to the greater public good [37,38], debilitating factors in public sector impinge on their desire to consistently contribute their services for citizens. In such a situation, increasing work motivation and infusing the spirit of public service could not only achieve the goal of enhancing work performance, but also positively influence employee satisfaction [39]. Moreover, removing the debilitating factors could also help in sustaining the motivation and morale of public sector employees.

\subsection{The Interplay and Disentanglement between Intrinsic and Extrinsic Motives}

A number of previous studies [13,37-40] show that public sector employees have higher intrinsic motivation and that extrinsic monetary incentives carry less value for them. In his seminal work, Hall G. Rainey [7] empirically demonstrated that public sector employees have a higher level of altruistic behavior, resulting in higher PSM [22,41,42].

Intrinsic motive is driven by an interest or enjoyment of the task itself, and exists within the individual, rather than relying on external pressures or a desire for reward [43]. For instance, strong intrinsic motives could instill a sense of belonging, loyalty to the country/organization, feeling of ownership, and a sense of responsibility. Ryan and Deci [44] characterized intrinsic motivation "as doing something because it is inherently interesting or enjoyable", whereas extrinsic motivation refers to "doing something because it leads to a separable outcome" (p. 55) [44]. They further explicated 
intrinsic motivation by positing that it is vital to keep the intrinsic motive high, or it may otherwise be subdued and undermined by a host of internal and external factors (p. 70) [44]. Although both public and private sectors may have intrinsic motivation, the public sector has an edge of stronger intrinsic value, given its mission of serving citizens and nation as a whole. This corresponds to previous research conducted in various settings that illustrate that the public sector offers stronger intrinsic value than the private sector $[15,39,40,42]$. Public sector employees, therefore, are more likely to be motivated by intrinsic, rather than extrinsic, rewards $[45,46]$.

Extrinsic motivation, however, remains an inextricable component of overall motivation because it largely involves the monetary benefits and non-monetary incentives, such as the expectation of promotion, opportunities for lateral moves, developmental plans, and job enrichment. Jensen and Bro [39] claimed that PSM has both autonomous and extrinsic characteristic (p. 3), whereas Ryan and Deci [44] maintain that much of what people do is largely extrinsically motivated (p. 71) and that, for the most part, every intrinsic motive has an invisible extrinsic motive attached with it. Ryan and Deci further suggested that extrinsic motives represent active and agentic states (p. 55) [44] and contribute significantly in enticing individuals to exert more efforts and energy towards accomplishing a task.

Some scholars consider intrinsic value as a distinctive feature of PSM [22,40], and suggest that intrinsically motivated individuals are drawn to public service for the altruistic aim of serving the public [41,47]. Kim [42], however, asserts that PSM can be "characterized as a reliance on intrinsic rewards over extrinsic rewards" (p. 726; also see Bozeman and Su) [48]. Contrary to this notion of public sector as "purely intrinsic-oriented", Weske and Schott [49] maintain that individuals are driven by several motives simultaneously, both intrinsic as well as extrinsic motives (p. 416). Moreover, since pay-for-performance systems may not gain much success in enticing public sector employees given their preference and inclination toward intrinsic rewards [50], public sector organizations need to find alternative ways of stimulating and galvanizing employees. Houston [50] suggested that the motivational tools prevalent in the private sector may not be as effective and applicable in the public sector, as they are in the private sector (see p. 81).

\subsection{Basic Psychological Needs and Self-Determination Theory (SDT)}

Edward Deci and Richard Ryan's seminal work of self-determination theory (SDT) [44,51], posit that an individual's personality traits and motivation are driven by inherent growth tendencies and that individuals are liberally endowed with intrinsic motivational tendencies (p. 70). Individuals seek work that they think may satisfy their own inner self and interests. This idea explicates the motivation behind the choices people make without external influences. However, the consistency and enhancement of this growth tendency require a supportive environment as it can easily be disrupted by non-supportive conditions. Deci and Ryan [51], and later Ryan and Deci [44], assert that the type of motivation is more important than the amount of motivation. They categorized motivation into two types, i.e., autonomous and controlled motivation. Autonomous motivation refers to the situations when individuals have a full sense of willingness, volition, and choice to do something $[39,52]$. People enjoy doing such activities and feel value in it. Contrasting controlled motivation characterizes that individuals are willing to do something with an expectation to get a reward for doing it [39], obliged to do or to avoid some kind of punishment, or to offset some kind of social or work pressure. When people are autonomously motivated, their wellness, performance, and engagement, etc., are greater as opposed to controlled motivation.

All human beings have a set of basic psychological needs, which Ryan and Deci [44] categorize as (1) "Need for competence - to feel confident and effective in doing things; (2) The need for relatedness- to feel cared for by others and to care for others and to feel that you belong to various groups that are important to you; (3) The need for autonomy — that entails that the need for autonomy must be satisfied for optimal wellness and optimal performance, and negative psychological consequences may follow if these needs are not satisfied. SDT further explains that when people are competent and when they feel related to others, they will feel a sense of volition — then they will be autonomously motivated 
and positive consequences will follow. SDT emphasizes creating the circumstances for individuals to perform at their optimum such that the outcome of their efforts will be optimal [51,52]. This theory has practical implications and relates to our argument of removing the inhibiting factors and barriers to performance which will help enhance employee motivation and morale.

\subsection{PSM as Dynamic Versus Impervious}

When Perry and Wise proposed PSM theory in 1990, they assumed that PSM is a dynamic attribute and may change over time (p. 370) [9] as a result of organizational factors and changing circumstances. Later studies have shown mixed results on the question of PSM being a dynamic or static state; Bakker [53], for instance, maintains that PSM can decrease significantly if job demands are high and job resources are comparatively low, while Kjeldsen and Jacobsen [24] found a decrease in PSM as a result of reality shock. Similarly, Yung [25] found a declining motivation after entry to a career in the public sector. More interestingly, Braender and Andersen [54] argued that there is not a single answer as to whether PSM increases or decreases post-entry to public service, rather that the different dimensions of PSM exhibit different patterns of increase or decrease. They conclude that PSM can change considerably when an individual is exposed to a dramatic event such as deployment to war. In such a situation, the PSM dimension of compassion decreases as soldiers become more normatively and less affectively motivated during deployment (p. 475). By analyzing the interplay between organizational socialization and PSM, Lee and Kim [55] attempted to explore the static versus dynamic state of PSM in a longitudinal study in South Korea, and maintained that the direction and level of PMS change varies for subdimensions of PSM, such as commitment to public interest and self-sacrifice, which decrease while compassion increases over time (pp. 122-123). Further, a superior's role contributes positively in enhancing PSM, while co-workers' roles have not been found to induce a significant change in PSM (p. 122) [55].

Wright and Grant [56] pointed out an important dimension of PSM by arguing that if PSM is considered a stable trait or is difficult or slow to change, then efforts to manipulate it as an independent variable in various studies is likely to be fruitless (p. 693). Echoing a similar opinion, Christensen, Paarlberg, and Perry [57] posit that PSM does not appear to fluctuate widely during the formative years of entry to public service, and it seems neither to be fixed nor fluctuating unpredictably though, however, that the organizational practice may influence PSM change (p. 531). Gabris and Simo [58], in contrast, argue that only top management and employees at the highest echelon in the public sector could be imbued with public service motivation, whereas for middle level (even the technical and professional staff) and shop-floor employees, it is just a secure job with decent benefits (p. 40) [58].

Thus, the stability versus dynamic nature of PSM remains a mystery and has yet to be fully explored because scholars have found mixed results and provided conflicting explanations for ascertaining the stable versus dynamic nature of PSM. Conventional wisdom tells us that PSM may change drastically during natural calamities, such as forest fires, tsunamis, or earthquakes, or during man-induced disasters, such as acts of terrorism. Therefore, it seems unreasonable to believe that PSM is a stable trait that remains constant at all times, and that rather, it could fluctuate with the changing circumstances in internal organizational and external environmental factors.

\subsection{Total Quality Management (TQM) as a Way Forward to Enhance Motivation}

Given the diminishing motivation of public sector employees over time, TQM, like any of a number of leadership and management approaches, can be a specific tool or agent in boosting the motivation and morale of public sector employees. As mentioned earlier, the major causes of demotivation for newcomers in public sector are the reality shock [23] and red tape [30,35]—resulting in inefficiency, inflexibility, and myriads of non-productive processes, and causing much annoyance and frustration to employees. Remedying the problem through TQM is, however, often easier said than done. TQM programs have not always proven to be successful, and many TQM initiatives often fail to create a deep and sustained change in organization [59]. Reasons for the failure of TQM improvement initiatives 
range from the lack of ownership and commitment at top management to the ambiguity and lack of clarity at the middle and implementation level, to deficient allocation of resources (financial, human, materials, knowledge, etc.) or failure to institutionalize TQM in the organization-to name but a few. Nevertheless, TQM, if carefully planned, implemented, and institutionalized in organizations, can bring about significant results. There is also a congruence in values between TQM and PSM philosophies-both strive to better serve the customers (citizens and community). Moreover, TQM also emphasizes the adequate training of the workforce, and is both skill-based as well as attitudinal, which can contribute in enhancing the PSM of public sector employees.

Customer satisfaction, as the core value of TQM philosophy, strives to bring improvement and quality across the board through improvement in work processes, customer service and satisfaction, interdepartmental and employee coordination, expeditious carrying out of tasks and work processes, and a proactive approach to anticipating and solving underlying issues. This all leads to better coordination, cooperation, and synergy amongst various organizational units and employees in a department, which ultimately contributes in enhancing employee motivation to accomplish task in a team-oriented and supportive work environment. TQM can also help in emboldening the ownership with organization, as TQM principles emphasize the active involvement of employees in the decision-making process and adequately reward the good performance.

Moreover, improvement and efficiency in work processes will also transform the organizational culture, as a conducive and congenial organizational culture is positively correlated with job satisfaction and work motivation $[30,60]$. In addition, enabling work environment and socialization process can help induce positive energy, which contributes to boosting work motivation and PSM [21]. However, TQM tools need to be molded and customized to address the specific needs of the public sector agency [61] in order to yield the desired results. While TQM can afford significant improvements in employee motivation and organizational performance, its prerequisite is full organization-wide deployment, and faithful attention to details in implementation. From an individual organizational leader's or manager's viewpoint, TQM requires an organization's full commitment for success.

\subsection{Complex Nature of Public Sector Work}

For individuals passionate in serving the public interest, public sector jobs represent an ideal choice for an opportunity to make a difference to their communities [62]. However, if not clearly aware of the unique nature and dynamics of public sector work, they may lose motivation and face frustration [31]. Since public sector organizations often deal with the complex and big picture issues confronting the nation $[63,64]$, the work and functions of public sector organizations are highly complex and challenging [65-67]. Oftentimes, it can be chaotic and frustrating. These conditions can erode PSM-public service is not something that everyone savors. However, for individuals acclimatized to the work of public sector organizations, this chaos and confusion is just part of their job, and they believe that this is just how public sector organizations function. Individuals imbued with the spirit of public service knowingly sign up to embracing uncertainty and challenge for the larger cause of making a difference in communities.

\section{Literature Review}

There are varied arguments regarding the role of literature in grounded theory, and the opinions are somewhat conflicting. A majority of scholars, including Glaser and Strauss [68], Strauss and Corbin [69], and Charmaz ([70,71] have advised being careful in the use of the existing literature, as it may pollute and overshadow any new and/or unique discovery that could be drawn from the data and the research, and that may be precluded under the influence of preconceived notions [72].

\subsection{Public Service Motivation (PSM)}

Motivation in public sector organizations differs distinctively from motivation in private sector organizations [8,9]. The difference arises because the mission and reason for existence (goals) is quite different for private and public sector organizations, i.e., the former fundamentally exists for profit, 
whereas the latter has a mission of serving the larger public interest. Motivational factors, therefore, are quite distinct between employees working in public or private sectors. Brewer, Selden, and Facer II [73] explored individuals' motives for joining public service using $Q$ methodology, and identified four distinctive types and motivational profiles for joining public services: Samaritans, Communitarians, Patriots, and Humanitarians. They further posit that PSM is more complex than predicted in previous studies, and the motives for performing public service are mixed (p. 261) [73].

PSM is a subject of debate both in academia concerning public service as well as for practitioners in dealing with human capital in public sector organizations. Staats [74] suggested that "[i]n its broadest sense, 'public service' is a concept, an attitude, a sense of duty-yes, even a sense of public morality" (p. 602) [74]. The widely used definition of PSM, however, comes from Perry and Wise (1990) who describe PSM as "an individual's predisposition to respond to motives grounded primarily or uniquely in public institutions and organizations" (p. 368) [9]. Brewer and Selden [13] called it a "public service ethic" and characterize it as "the motivational force that induces individuals to perform meaningful public service" (p. 417).

PSM may be also be influenced by the socialization process within the organization and external socioeconomic conditions. Moynihan and Pandey [30] examined the antecedents of public service motivation, the role of sociohistorical context, and how organizational factors play a role in shaping public service motivation [25]. Their findings support the importance of sociohistorical context, showing that public service motivation is strongly and positively correlated to the level of education and membership in professional organizations. Whereas, in drawing a sample from the Australian public and private sectors, Taylor [75] empirically tested the relationship between organizational factors (such as intrinsic and extrinsic rewards, work relationship within an organization) and PSM. Her findings suggested that individuals with high public service motives show a preference for government employment, but once they are employed by their organizations, the workplace culture, including the organizational policies and practices, influence the strength of the employees' PSM. In Denmark, Jacobsen, Hvitved, and Andersen [76] explored the effect of external interventions-such as command systems and financial incentives - on employee public service motivation, and found that these factors may decrease motivation.

Although PSM theory put forward by Perry and Wise [9], with the subsequent measurement tool by Perry [10], has been a breakthrough in application of PSM, their theory and measurement tool is not free from criticism. One of the criticisms is that the PSM theory and measurement tool gives us little information about what motivates public sector employees and what actually causes motivation to ebb and flow in the careers of public sector employees [21]. Although few studies use unconventional research designs, such as experimental design by Bellé [17], longitudinal data by Vogel and Kroll [32], and a qualitative study by Andersen et al. [77], a large amount of PSM scholarship is based on quantitative survey research design (p. 712) [23]. The survey research design, although widely used in various situations, is not good at drawing out more nuanced insights than other alternative ways of exploration which may be more suitable. Putting it differently, the survey instrument may not necessarily reflect the actual feelings and aspirations of the employees as it restricts the respondents to respond and comment using predefined closed-ended questions.

A small, but growing, stream of studies attempt to compare the public service motivation pre-entry and post-entry to public service. Through a longitudinal study using the panel data from Danish physiotherapists, Kjeldsen and Jacobsen [24] examined the PSM and employment sector before and after their first job choice in the public and private sector, and found that PSM is not relevant for attraction and employment in public sector. Rather, they revealed the striking finding of PSM being severely impeded after job entry, known as "shock effect" (p. 899) [24]. This shock effect could be attributed to various internalities, such as red tape $[7,24,30]$, incompatible working relationship with the elected officials, inflexibility and exhaustive work processes, and external factors such as undue political influences, citizens' disengagement, challenges in acquiring funding from state and federal governments, to name but a few. Moreover, the nature of job responsibility and changes in circumstances may also induce fluctuation in the degree of PSM (both upward and downward); 
for instance, during times of natural disasters such as forest fires, the public service motivation of individuals serving the nation, as well as the general public, increases many-fold. Similarly, during times of economic depression, PSM may plunge significantly, whereas during a time of war, the PSM of serving individuals as well as citizens heightens with the spirit of serving the nation. In the United States, Brænder and Andersen [54] examined the effect of war on soldiers' public service motivation, and how it the effect was moderated by early war experiences. They concluded that after deployment to war, compassion decreases and commitment to the public interest increases (p. 473) [54], and in such war situations, "soldiers are normatively motivated as opposed to affectively motivated" (p. 475). Through a survey of civil servants in government organizations in South Korea and taking into account the organizational socialization process in influencing PSM, Lee and Kim [55] attempted to explore the conundrum of whether PSM is a static or dynamic state, and concluded that "organizational socialization factors influence PSM change" (p. 122), and they identified six factors that catalyze PSM change, such as "role model and identification, experience and action, work content, role model and identification, experience and action, and work content".

In order to discover the subtleties of the phenomenon, scholars called for unconventional and alternative methods of scientific inquiry, such as experimental design and longitudinal studies [78]. Attending to the call for experimental design, some scholars, including Bellé [17] and Pedersen [79], conducted experimental studies [57]. By conducting a field experiment in a public hospital in Italy, Nicola Belle investigated the interplay between job performance and PSM, and found a positive relationship between PSM and performance. While delving on whether PSM is dynamic stable or a dynamic state, Bellé [17] posits that "PSM is a dynamic state, or at least a trait showing significant within-person variability" (p. 150). Further, the level of PSM at a given time is influenced in a way that is attributable to attraction-selection attrition, as well as through organizational processes [17].

The relationship between PSM and eco-friendly initiatives, however, seems sparingly addressed in the scholarly literature on public management. By hypothesizing that "PSM will be positively related to an employee's participation in eco-friendly initiatives", Stritch and Christensen [80] conducted empirical studies in a large municipality in the United States, and concluded that the connectedness to nature, organizational commitment, and PSM are significant predictors of eco-friendly initiatives in the public sector" (p. 1). Other than the collective organizational efforts, the public sector employees also individually strive to make a positive impact on environment (p. 14) [80], and actively participate in eco-friendly activities and initiatives to improve their surroundings.

While PSM has been tested positively in many countries around the world, some scholars found pitfalls in existing PSM instrument. In South Korea, Kim and Kim [81] found a strong indication of social desirability bias in the PSM construct, and posit that if respondents perceive the questions to be sensitive, they are more likely to give a socially desirable response as opposed to their actual opinion in the PSM survey (p. 294). Whereas the majority of studies have shown positive outcomes and consequences of having higher PSM in public sector employees, in Denmark Jensen, Andersen and Holten [82] discovered the flip side of the coin, i.e., the potential negative consequences of high PSM. They conducted a three-wave panel study of public and private sector employees and explored the "dark side" of PSM. They found a strong positive linkage between PSM and presenteeism, and indications that the PSM-absenteeism link is mediated by presenteeism (p. 1) [82]. Moreover, Schott and Ritz [83] also shed light on the dark side of PSM and feared that having strong Compassion dimension of PSM measure could potentially lead to unethical behavior as being too compassionate could jeopardize the neutrality of public servants (p. 2). They further maintained that some public sector jobs, such as teaching and nursing, that attract individuals with high PSM have ended up in burnout because of demanding and stressful working conditions.

\subsection{Sustainable Development Goals (SDGs) and Sustainable Motivation}

The United Nations defines sustainability as "meeting the needs of the present without compromising the ability of future generations to meet their own needs (United Nations Academic 
Impact) [84], whereas we operationally define sustainable motivation as "the sustained and consistent high degree of motivation, and resilience to forces of negative change that could cause motivation to ebb and flow". Sustainability has been a long-debated topic in academic literature as well as in the corporate sector. It received a boost in 2015 when the United Nations General Assembly passed the resolution to adopt the Sustainable Development Goals (SDGs) for 2030. Emanating from the Millennium Development Goals (MDGs), SDGs are 17 goals aimed to address the three broader areas of intervention, i.e., economic, social, and environmental sustainability. SDGs focus on five key elements, i.e., people, planet, prosperity, peace, and partnership, and "people" are the center of locus and an integral part of the SDG goals and targets. The attainment of SDGs requires the active engagement and contribution of all stakeholders, including government, private sector, non-governmental sector, higher education institutions, philanthropic organizations, media, and civil society [85]. The SDG goal 16.6 emphasizes strengthening public institutions for infusing new thinking, strategy, and action towards building effective and accountable public institutions [85].

The role of the public sector employees in implementing and attaining the targets of MDGs and SDGs is undeniable. Whereas the role of every stakeholder is significant in implementing the SDGs, the role of the public sector is, however, highly crucial for the planning and execution of programs. The United Nations Development Programme (UNDP) has reported that the intrinsic motivation and morale of public sector employees is declining around the world [86]. The report further suggests that the active engagement and motivation of public officials have been diminished given the perceived organizational and procedural injustices, unprofessional performance assessments, and unfair recruitment decisions (p. 1) [86]. The leadership in public sector organizations need to make concerted efforts to stimulate and galvanize their workforce as the public sector is labor-intensive, and many of the tasks and activities carried out by the public sector require active engagement of workforce, contrary to the private sector where machines, tools, and technology have taken over much of the labor roles. Moreover, human resources and SDGs are interconnected through the common component of the human factor, since people's attitudes, behaviors, and resource consumption have a direct impact on social, economic, and ecological practices (p. 110) [85,86].

\section{Data and Methods}

This study is an exploratory qualitative study, and the unit of analysis is individual. The study employs the constructivist grounded theory (GT) method which consists of systematic collection, coding and analysis of qualitative data to construct theories 'grounded' in the data [68,70]. Alan Bryman and Emma Bell [87] termed it an iterative and recursive approach to data collection and analysis, where both processes move back and forth (p. 428). Since the first discovery of grounded theory by Glaser and Strauss [68] some five decades ago, extensive scholarship has been made in further refining and making it one of the first choices in qualitative research. Karen Locke [88] termed it the most widely used method in qualitative inquiry.

The decision to adopt the grounded theory method of qualitative inquiry is based on the vacuum in the existing literature on PSM which has generally focused on addressing the current state of PSM, whereas motivation, being a human behavioral phenomenon, could drastically change with changing circumstances. Patton [89] posits that behavioral and social phenomena can be better uncovered through qualitative methodologies, which have gained more popularity and acceptance in recent years. Moreover, GT is more appropriate for the study themes exploring the lived experience of subjects and where there is little known about the topic [90]. Hence, our study theme appropriately fits into the grounded theory inquiry.

Thick quality data has been gleaned through in-depth interviews because interviews are suitable for investigating complex theoretical concepts, and where the theory has shortcomings in its operationalization $[23,91]$. The study subjects have been objectively chosen, keeping in view the study objectives as well as adhering to the GT philosophy through purposive sampling [92]. Purposive sampling is adopted to garner in-depth insights about the phenomenon under investigation, as the 
study participants possess attributes important to understanding the research topic [93]. The study sample comprised of local government (LG) employees, as LG is the place where public servants have a direct and intimate interaction with citizens. It is also a place where both tangible and intangible impacts can be made on the communities. Secondly, regarding the United States in general, and the State of Oregon in particular, the local government system is highly functional, effective, and impactful. The study sample includes both senior and junior respondents who weigh in the variations in responses of the three hierarchies and generations of employees, i.e., (i) top executives such as County Administrators, Chief Administrative Officers, City Managers; (ii) mid-career professionals having 10 15 years' experience in the public sector, such as human resources Directors/Managers; (iii) and younger employees under 30 at an entry level position, to gauge the variations of responses across generations and hierarchies.

Twelve local government jurisdictions have been chosen, comprising of local governments in Cities and Counties in the State of Oregon. These jurisdictions (Cities and Counties) have been carefully chosen to reflect both an urban, suburban, and rural combination, in order to obtain the diversity of thoughts and insights. Eight out of twelve jurisdictions have responded positively and shown their willingness to participate in the study, hence, the response rate remained at $66.6 \%$. The rest of the other four jurisdictions have not turned up despite repeated requests and follow-up emails. For the purpose of confidentiality and data protection, the names of the jurisdictions as well as the study participants have been kept anonymous and given pseudonyms.

\subsection{Grounded Theory (GT) Research Process}

Adhering to the GT principles, the following research process has been adopted to meticulously and rigorously collect and analyze the thick qualitative data (see Figure 1).

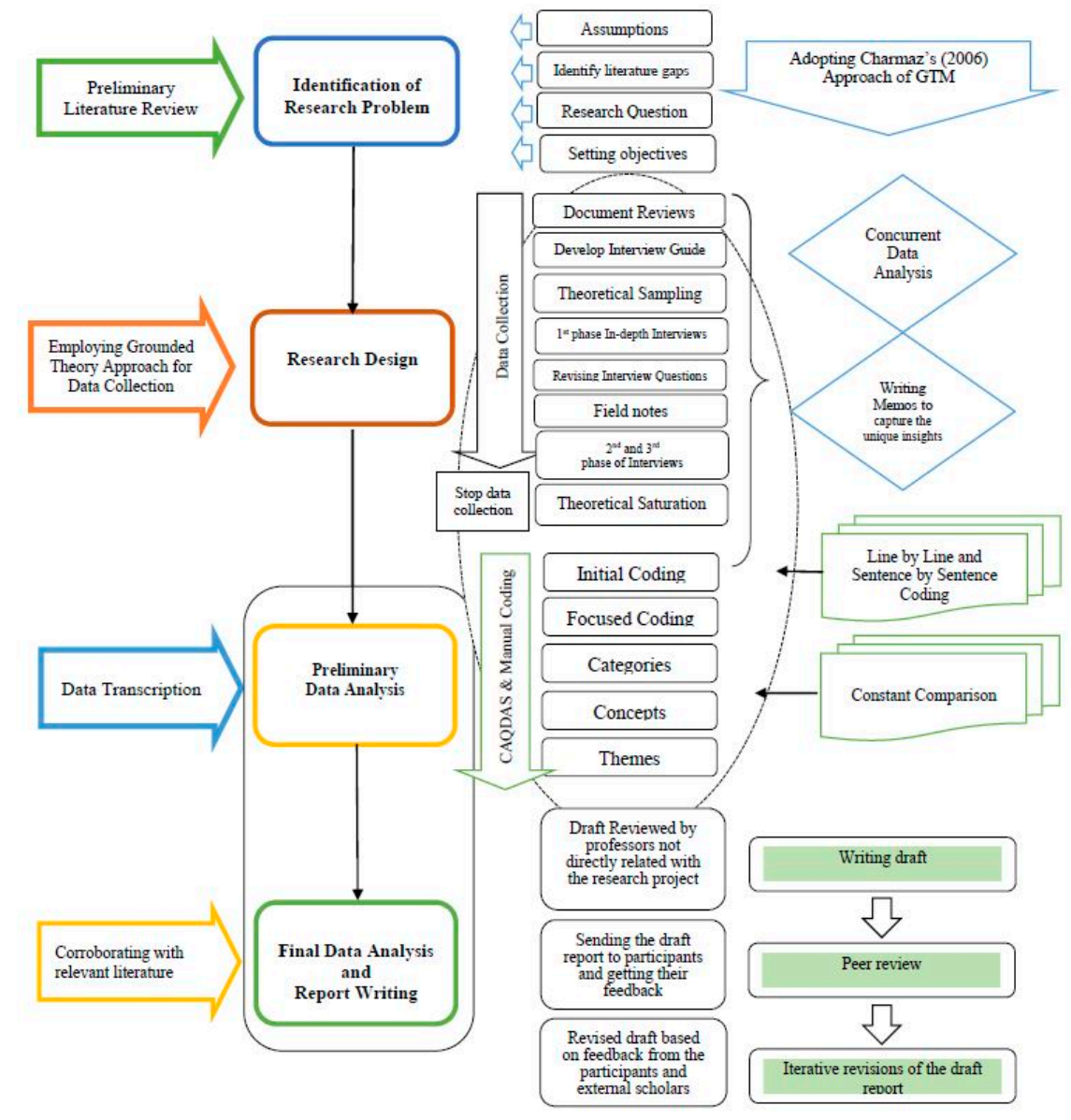

Figure 1. Grounded theory research process. Source: Authors' curated. 


\subsection{Demographic Information}

The study subjects have been carefully chosen to get a thick description of the qualitative data. Mid-career professionals of the age bracket $31-45$ year constitute $36 \%$ of the total sample, which is slightly higher than the two other cohorts, whereas the younger employees under 30 years and senior executives of 46 years and higher each comprised 32\%. Figure 2 illustrates the rural/urban and hierarchical distribution of study participants.

The diversity of study sample helped in cross-comparison of responses, especially to weigh in the thoughts of the entry level and millennials employees with those of the mid-career and senior executives. The millennials' thoughts about public service and public sector jobs provided the most interesting insights as did the senior executives' sharing of their lifelong experiences and career in public service. The gender ratio indicates that an increasing number of women are opting for local government jobs and contributing their services for the communities. The study sample, in terms of gender, was reasonably proportioned, as shown in Table 1.

Table 1. Study participants' demographic information.

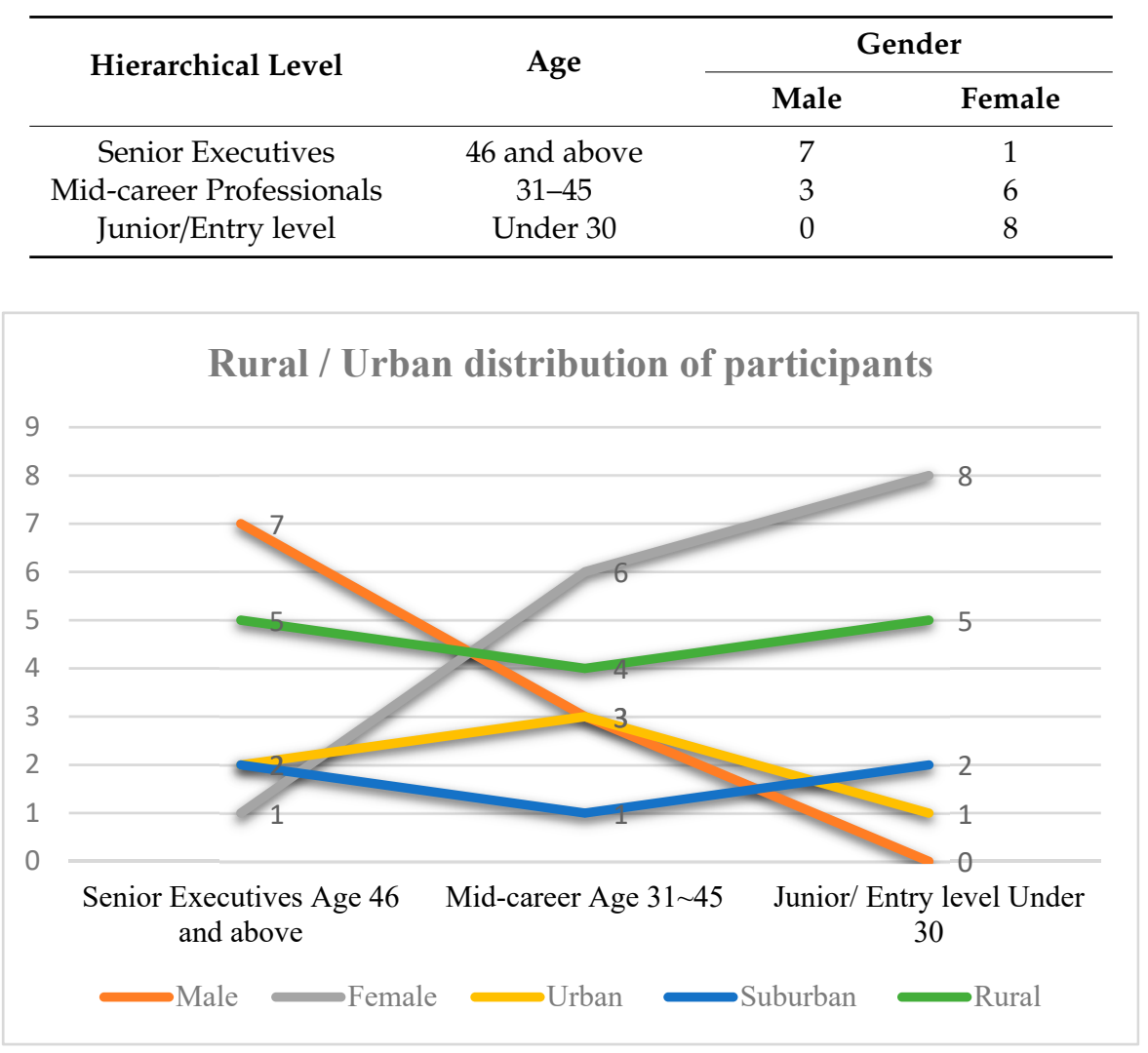

Figure 2. Rural/Urban distribution of study participants.

\subsection{Setting}

Local governments are responsible for a host of functions in their jurisdictions, including but not limited to zoning, fire services and police protection, budgets, garbage collection and waste disposal, school governance, water filtration plants, sewer, administration and maintenance of local parks and recreational areas, street maintenance, building permits, libraries, handling affairs related to minority communities, to name but a few. These activities and programs directly and indirectly contribute in individual and community quality of life [94]. The local governments collect various taxes from citizens, businesses, farms, properties and other entities to generate revenue for running governmental affairs.

There are approximately 90,000 independent local governments functioning in the United States (p. 55) [95], whereas the state of Oregon has a total number of 1542 local governments, consisting of 36 
counties, 241 cities and municipalities, 1035 special districts, and 230 independent school districts [96]. In terms of employment, local governments employ more than the state and federal government at the local levels, as the total government employment in the State of Oregon is 243,555, of which local governments occupy $66.2 \%$ of the total employment in the State [96].

\subsection{Recruitment of Study Participants}

The invitation to participate in the study was sent through official emails, clearly explaining the purpose and other modalities involved in the interview process, and to solicit their participation in the study. Upon receiving a positive response from the potential participants, the Informed Consent Form has been sent to their email, which further clarified the study objectives, details of the interview process, rights of the participants, any risks attached to participate in the study, and permission to voice record the interview for transcribing purposes. A sample of Informed Consent can be found in Appendix A (Table A1). The participants willing to take part in the interview process responded by email and sent a signed copy of Informed Consent. Since participation in the study was purely voluntary, the participants were given the choice to withdraw from the study at any time before, during, or after the interview. Table S1 illustrates the sample interview guide, however, in line with the GT philosophy, the actual interview went beyond the questions mentioned in the interview guide, and the participants have been given the flexibility and liberty to share their thoughts in an open and comfortable way.

Since the study involves human subjects, formal approval was acquired from the Human Subjects Research Review Committee/Institutional Review Board (HSRRC-IRB) of the Portland State University (PSU), United States, by fulfilling the requirements of full review and adhering to the guidelines and protocols set forth for the human subjects research. Additionally, the researchers have gone through the required training course of "Protecting Human Research Participants", conducted by the National Institutes of Health (NIH) office of Extramural Research.

Before embarking on garnering data, the researchers formally obtained consent/assent from the participants multiple times. First, the consent to participate was obtained by contacting the potential participants through email, describing the complete details of the study, such as the purpose, data collection, usage and data protection, etc. Once the participants gave their consent to participate via email or telephonic conversation, formal Informed Consent together with the project description was sent prior to the personal interview. A signed copy of the Informed Consent form was retained by the participants so they may contact PSU-HSRRC and/or the researchers should they have any concerns about the study. Study participants have been given the choice to choose the place of their interview, either at their workplace or at a PSU boardroom and we ensured privacy and minimum distractions.

\section{Findings}

Following a GT approach, preliminary data analysis was concurrently carried out during the data collection process. This helped in reframing and refining our questions each time and to garner stronger theoretical insights from the study participants. Thick interview data has been transcribed verbatim and an intensive process of coding has been carried out in data analysis process (Table 2 illustrates a sample coding process).

A diverse array of respondents in both senior, mid-career, and junior ranks shared their unique stories of serving the public, the challenges they grappled with, and the high and low points of their career. Through a free-flowing conversation with the local County Administrators, City Managers, human resources (HR) professionals, and younger employees of the local government in the State of Oregon, we explicated the factors that cause employee motivation and PSM to wax and wane, and how TQM principles could help in sustaining motivation. Thoroughly conducted in-depth interviews yielded rich qualitative data, and the careful and meticulous analysis of the data evinces many interesting insights reflected in the following section (Table 3 presents an abridged summary of findings). 
Table 2. Coding process: Generation of focused codes, categories, concepts, and themes.

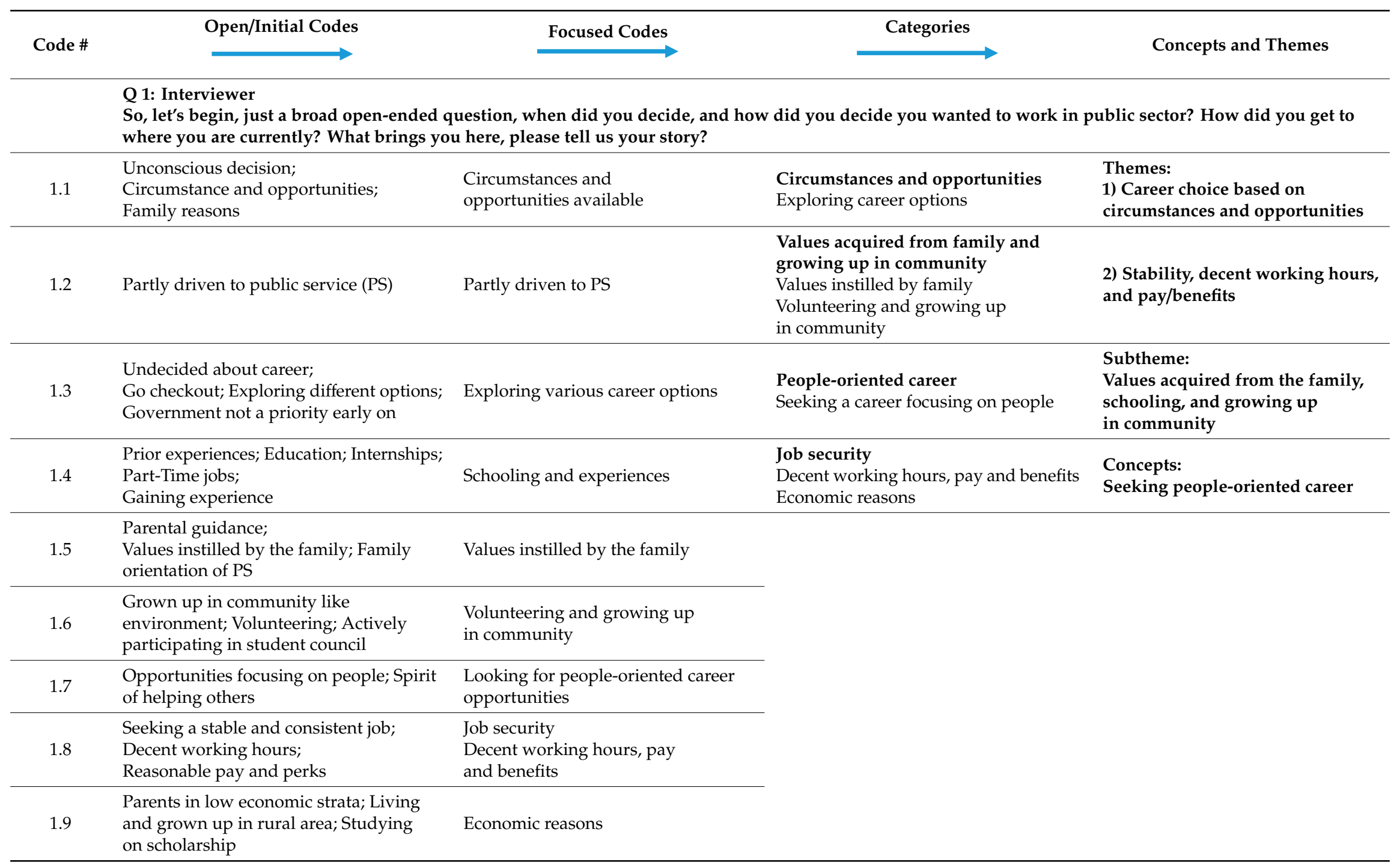


Table 3. Summary Rubric.

\begin{tabular}{|c|c|c|c|c|}
\hline & Description & Junior Employees & Mid-Career & Senior Executives \\
\hline 1. & Sector choice & Instrumental reasons & $\begin{array}{l}\text { Partly opportunistic and partly driven by } \\
\text { desire to serve public interest; } \\
\text { Being influenced by people around; } \\
\text { Desire to find a stable job for various reasons }\end{array}$ & $\begin{array}{l}\text { Careerist; Conscious and purposeful } \\
\text { decision to serve public interest; } \\
\text { Value alignment-personal values meshing } \\
\text { together with the organizational values }\end{array}$ \\
\hline 2. & Motivation boosters & $\begin{array}{l}\text { Variety of work; } \\
\text { Decent working hours; } \\
\text { Transparency and fairness; } \\
\text { Community outreach }\end{array}$ & $\begin{array}{l}\text { Job security and stability; } \\
\text { Sense of contributing to public good; } \\
\text { Fascination for public service; } \\
\text { Seeing community thriving }\end{array}$ & $\begin{array}{l}\text { Meaningful work; } \\
\text { Seeing the impact of the work; } \\
\text { Intrinsic value; } \\
\text { Making a tangible contribution } \\
\text { in communities; } \\
\text { Solving the real community issues }\end{array}$ \\
\hline 3. & Motivation dampeners & $\begin{array}{l}\text { Lack of flexibility; } \\
\text { Red tape and slow processes; } \\
\text { Citizens' undue complaining about } \\
\text { the government; } \\
\text { Apathetic attitude of the managers } \\
\text { and higher-ups; } \\
\text { Micromanaging }\end{array}$ & $\begin{array}{l}\text { Red tape, procedural complexities and } \\
\text { rigid rules; } \\
\text { Stereotypical attitude of public towards } \\
\text { the government; } \\
\text { Fear of redundancy and ripple effects; } \\
\text { Seeing dwindling motivation of colleagues; } \\
\text { Diminishing work-life balance; } \\
\text { Discouraging feedback from colleagues; } \\
\text { Negative news and government bashing } \\
\text { in media }\end{array}$ & $\begin{array}{l}\text { Anti-government rhetoric; } \\
\text { Demeaning government officials; } \\
\text { Challenges in dealing with elected officials; } \\
\text { Lacking concrete feedback from } \\
\text { the community; } \\
\text { Community disengagement; } \\
\text { Declining civility; } \\
\text { Crippling issues perturb, but resolve to } \\
\text { continue serving }\end{array}$ \\
\hline \multirow{2}{*}{4.} & \multirow{2}{*}{$\begin{array}{l}\text { Public versus Private } \\
\text { Sector }\end{array}$} & $\begin{array}{l}\text { Public sector: } \\
\text { Lack of ownership; Red tape; } \\
\text { Meaningful work }\end{array}$ & $\begin{array}{l}\text { Status quo oriented and resistance to change; } \\
\text { Complexity in dealing with labor unions; } \\
\text { Decent working hours; Accountability }\end{array}$ & $\begin{array}{l}\text { Structured and standardized work } \\
\text { processes; Opportunity of making tangible } \\
\text { and intangible contribution to community }\end{array}$ \\
\hline & & $\begin{array}{l}\text { Private sector: } \\
\text { Atrocious working hours; } \\
\text { Relentless firing; Flexible } \\
\text { work schedules }\end{array}$ & $\begin{array}{l}\text { More resources and individual authority in } \\
\text { spending budget; Fragile career; Lacking } \\
\text { working-life balance }\end{array}$ & $\begin{array}{l}\text { Temporary charm; Profit-oriented; Lack of } \\
\text { job security and retirement benefits. }\end{array}$ \\
\hline
\end{tabular}




\subsection{Factors Affecting the Sector Choice}

The data garnered through in-depth interviews shed light on many factors influencing the choice of career (see Figure 3). Individuals are driven to public service as well as the opportunities and circumstances that drift them towards the public sector employment. Consistency, stability, and security is one of the major attractions for individuals seeking a stable job for numerous reasons, including but not limited to family, desire to live in a specific place, perks and benefits, etc. In rural jurisdictions, public sector employment has turned out to be an ideal choice given the economy of the area and lack of enough opportunities in the private sector.

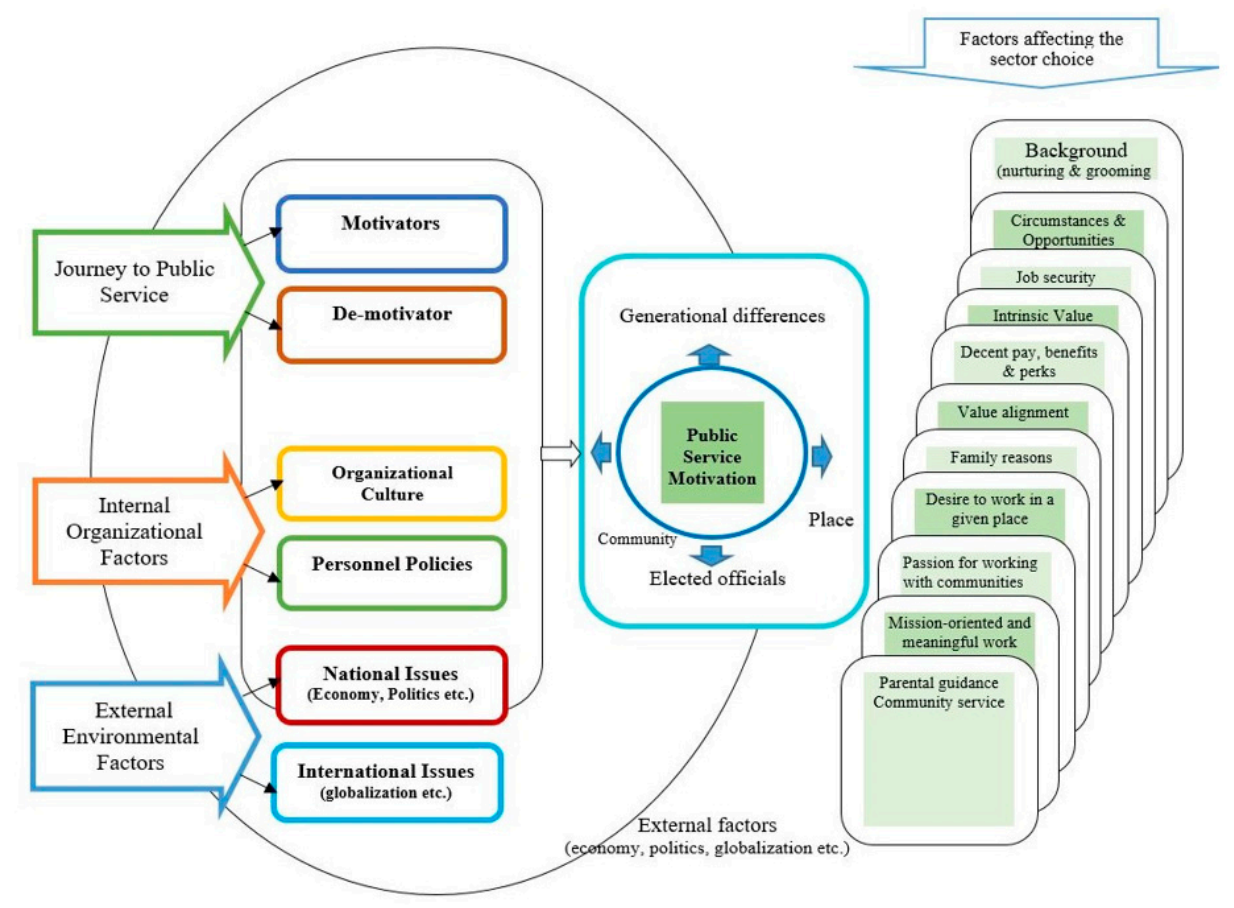

Figure 3. Proposed public service motivation (PSM) model: Factors directly and indirectly affecting motivation and PSM. Source: Authors' curated.

The model in Figure 3 construes that public service motivation is directly influenced by internal organizational factors, including but not limited to organizational culture and, to lesser extent, by the human resource policies, whereas sociogeographic place or geographical location play a significant role in shaping and strengthening (or otherwise weakening) the motivation of public sector employees. It is worth mentioning that the interview data reveal that PSM varies across generations and exhibits a different contextual explanation for the three organizational hierarchies (i.e., senior, mid, and junior).

Quadratic Model: Internal and External Factors of Influence

Figure 4 illustrates the relationship of internal and external factors that boost the motivation and morale of local government employees versus the factors that dampen it. Quadrant A shows the internal organizational factors that boost the motivation to serve in the public sector. The position in the $\mathrm{Y}$ axis shows their relative significance, e.g., meaningful work and touching people's lives is a stronger motive that induces individuals to serve in the public sector, whereas the other factors, e.g., flexibility of work schedules, seem relatively less prominent in keeping employees motivated. 


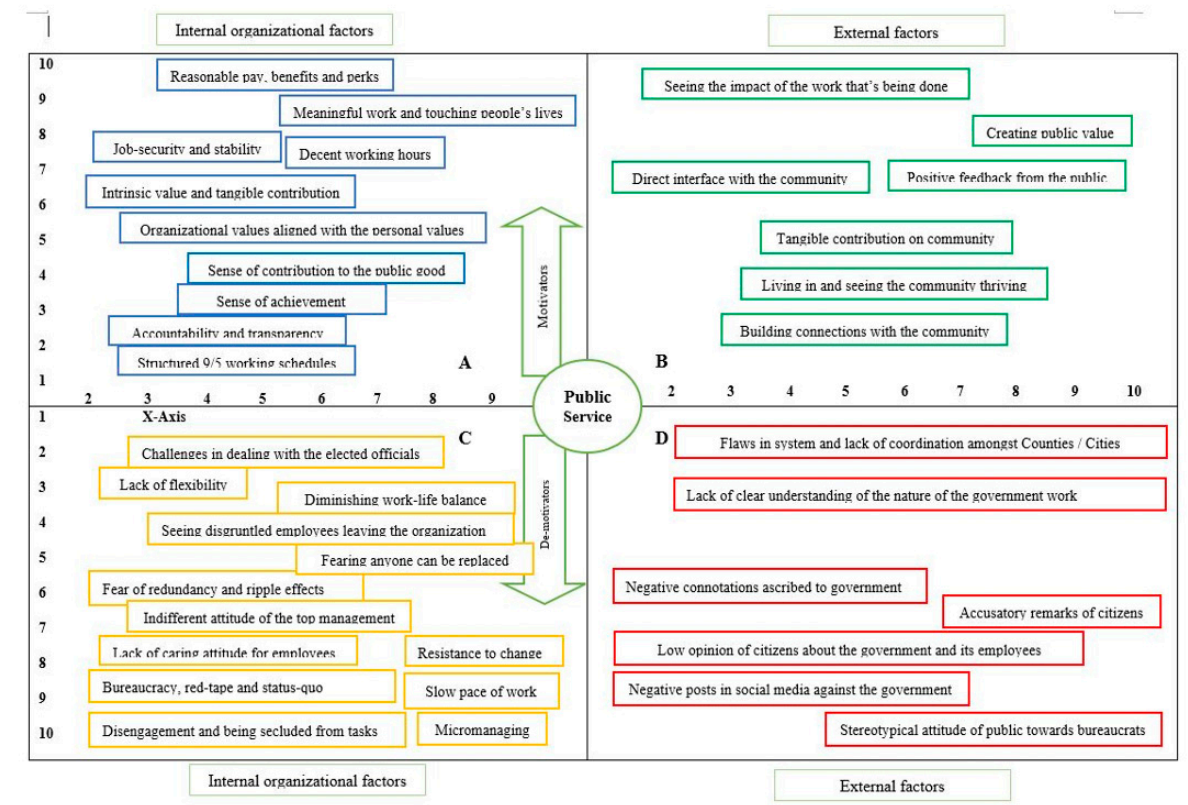

Figure 4. Quadratic model: Internal organizational and external factors affecting motivation. Source: Authors' curated.

Quadrant B is related to external factors that facilitate motivation, such as "seeing the impact of the work that is being done, creating public value and receiving positive feedback from the community". Quadrant $C$ shows the internal organizational factors that cause motivation to go down. As Figure 4 shows, most of the demotivating factors belong to this category and stronger de-motivators are perceived as being less worthy and disdain, indifferent attitude of the top management, and having poor managers who ruin the organizations. The external factors that cause de-motivation and dissatisfaction are relatively weaker compared to internal organizational factors, as shown in quadrant D. Hence, we can presume and construe from the interview data that individual and internal organizational factors are strong predictors in either boosting motivation and/or otherwise precluding and diminishing motivation.

With regard to attraction towards public sector, the influence of external environmental factors, such as churches, community, family, and schooling, play a significant role in building the spirit of public service, and Perry (2000) contends external influences are correlated with public service motivation [97].

\subsection{Factors Emboldening versus Eroding Motivation}

The study participants reminisced about their career span in public sector, and shared the myriad of factors that came into play in facilitating motivation versus undermining the spirit of serving for public interest. The major internal organizational factors boosting motivation turned out to be job security, stability, and decent pay and benefits. While external factors catalytic to enhancing public service spirit were creating public value through tangible contribution and seeing the impact of the work that is being done for the community, meaningful work with direct and intimate interaction with the community, and having community acknowledge and appreciate the work.

\subsubsection{Motivation Boosters}

A host of factors contribute in boosting the motivation and morale of employees in public service, such as the notion of touching people's lives, intrinsic value offered by public service, sense of achievement and working for the larger public good, creating public value and making an intangible 
contribution, to name but a few. The mission orientation of the public sector is yet another major source of attraction for individuals seeking meaningful work, as one respondent reflected upon:

[A]nd somewhere along the lines, I realized that I could apply for human resource management with those skills in any organizations, and I want to do with an organization with a mission, I needed to care about the product, I needed to care about the delivery of that organization [C.L-08, 08:05] (These citations refer to the interviewees' original remarks and the citations show their pseudonym instead of their original name in order to protect the identity of the interview respondents. The pseudonym is followed by the time and location of the cited comments in the transcribed taped interview of the respondents.)

Local governments, unlike the state and federal governments, have the unique opportunity to directly interact with and serve citizens and communities. This direct and intimate relationship makes local governments a place to make a positive impact and contribution in the lives of people in the communities. Local governments also enjoy the trust and confidence of their citizens, and in most of cases, the local governments are the first place of reference for the community. The embeddedness of local governing institutions in local communities is another source of motivation for employees serving the needs of their local communities, as they can see community growing and flourishing. Other positive factors are the variety of work because people take a keen interest in a variety of work for learning and growing. Organizational culture and having supportive colleagues makes a workplace thrive, and one respondent described her account of working in the private sector as toxic environment, and atrocious working hours [R.V-09, 00:48].

Public sector organizations being "public" have to exhibit a high level of fairness, accountability, and transparency in everything they do. Some respondents pointed out that transparency and effective accountability is a source of motivation, as everything is on public record.

Nevertheless, job security, stability, and flexibility of the tasks are generally the main source of attraction, as public sector jobs are generally ascribed with job stability and continuity. Like one respondent said: Yeah, the job is very secure here. I can't be fired without a reasonable justification. Whereas in X company (private sector) they were firing people on phone [A.W-03, 45:22]. Other extrinsic motives include decent working hours, and benefits and perks. Although public sector employment is often characterized by low pay and wages, the local governments in the State of Oregon seem to give reasonable pay and compensation, as reflected by employees in their contentedness. Nevertheless, some individuals are only motivated by money, and such people are in both the private sector as well as public. One senior executive concluded by saying: For some people the only way they could be motivated is to pay them three times more than what they are getting right now [D.B-13, 14:29].

\subsubsection{Factors Impinging Motivation}

Our data reveal that for some individuals, the initial motivation to serve in the public sector is hampered by various workplace factors, such as relationship with the boss, interaction with poor managers, fear of redundancy and ripple effects, lack of career advancement opportunities, flaws in the system such as too much dependence on managers and a combination of other factors, that contributed in diminishing motivation.

One respondent described her account of the factors that cast a dark cloud on her motivation as "being perceived as less worthy and too humanistic and employee-oriented" [C.L-02, 31:32]. This depleted her energy and put a damper on the motivation to serve. The subject termed it "draining motivation". The stereotypical attitude of the public towards the government and its employees is a major source of demotivation, whereas for some, it was just the way public sector organizations function:

I think though, perception of government for me personally more of a motivator, because I think people complaining about the government have no desire to actually get involved in changing the things that they are complaining about, nor they really understand what they are complaining about [A.W-03, 29:24]. 
Douglas McGregor's "Theory Y" postulates that human beings want to seek responsibility and would love to be engaged and involved in activities and decision-making processes; other major factors that preclude motivation are employees being secluded from the tasks and activities that they are supposed to perform, a lack of trust and limiting their responsivities and the scope of work, etc. As one respondent observed: "nothing is more demotivating than to sit in a cubicle and nothing to do now" [A.W-03, 16:37]. Conversely, if individuals see the outcome and impact of their efforts, they get highly motivated to perform and put extra effort in accomplishing the tasks assigned to them.

Our findings further explicate that individuals opting for public service are charged with the spirit of serving the communities with their full potential; however, their initial motivation to serve often diminishes in the wake of a number of factors, such as a lack of career progression opportunities, discouraging feedback from colleagues, such as not to put extra effort than was expected of a task, lack of respect and regard for public service, to name but a few. Of a graver nature regarding impeding the motivation to continue serving in public sector was the infamous notion that "anyone can be replaced and fear of redundancy and ripple effects" [S.S-01, 32:17].

Other factors that inhibit motivation are as follows:

(i) Indifferent attitude of top management: The apathetic and indifferent attitude of top management was more damaging to motivation and organizational culture as it permeates the whole organization. One female respondent in mid-career shared her account of the unsupportive and apathetic attitude in top management at her organization: It was, it was at the top of the organization at that time, the director level which influences, and permeates the whole organizational culture ... [S.S-01; 39:37].

(ii) The stereotypical attitude of the public: The biggest de-motivator is the low opinion that citizens have of the government and its employees. This is a major cause of the diminishing motivation in the public sector. Generally, the public has a stereotypical attitude towards the public sector employees and bureaucrats, and oftentimes, the public voice is to cut the public sector budget and bureaucrat's benefits, which means less services for the public, and this is generally not clearly understood by the public, regarding what it means and how it could adversely affect them. There is generally a lack of understanding of the work of the government, and how essential those services are for the citizens. One respondent put it this way:

So the public perception is so narrow focused, and they don't really understand the depth of their City or local government or State government does, and the differences between them. So the State government is very different than the Federal government and the local government is very different from the State government [A.W-03; 29:56].

A younger employee of the local government revealed that she has been surrounded by friends and other people who were very critical of the work of the government, and always taunted her for joining the government. She concluded by saying: "All the bad things that I heard about the government I don't think they are true" [S.S.-21; 29:58].

(iii) Social values placed on public service: Further on explicating the factors that erode motivation, one interview respondent compared the attention and regard given to celebrities versus public servants. The interview subject observed that public servants are not given the due regard and respect that they actually deserve in society for the kind of work and services they put in place for the larger public good. Their contribution to our society is enormous though they are, nonetheless, demeaned at times and/or their crucial role is misunderstood. Not-for-profit organizations (NPO), however, are more highly regarded in society as being a positive contributor to the social fabric.

\subsection{Total Quality Management (TQM) in Public Sector}

Total quality management (TQM) is a management approach concerned with people and work processes that focuses on customer satisfaction and aims to continuously improve work processes to elevate organizational performance. The three basic tenets of TQM are to focus on achieving customer satisfaction (both internal and external customers) as customer satisfaction is the bottom-line 
of TQM; seek continuous and long-term improvements in all areas; and take steps to ensure the full involvement of the entire workforce and management in improving quality. TQM requires an enterprise to systematically manage, coordinate, and improve all business activities in the interest of customers [98]. There is a huge potential of bringing improvement and change in the public sector by using TQM principles; nevertheless, the existing body of literature on management shows little evidence of the use of these principles in the public sector [99], although only a limited number of academic studies indicate the implementation of TQM and Lean techniques in the public sector, such as Yasin, Wafa, and Small [100], who conducted an empirical study of 86 public sector organizations in the United States and suggested the usefulness of the Just-in-Time (JIT) technique to increase the operational efficiency, service delivery, and organizational effectiveness of governments [99]. Some other examples of implementing TQM approaches in governments include the Connecticut Department of Labor [101] and the city of Cincinnati, Ohio, in the United States [102]. However, the culture of structured processes, red tape, inflexible and oftentimes rigid rules and bureaucratic delays make it highly challenging to fully implement the Lean and Kaizen techniques in the public sector.

Many progressive organizations adopt Kaizen and CI, but one of the challenges they confront is how to keep their employees fully engaged and stimulated in the improvement process. Nevertheless, no program of improvement and innovation can reach fruition unless the employees are motivated enough to carry it forward and the top management fully supports the change process.

\section{Applicability of TQM Principles in the Public Sector:}

Kaizen or Lean Thinking literally means "change for the better", inspired from Japanese Toyota Production System (TPS), which aims to reduce waste [99] in order to efficiently utilize resources and maximize output. Imai [103] ascribed Kaizen and Continuous Improvement as key to the Japanese industrial miracle in the 1970s and 1980s. Initially designed for the automotive industry in Japan [99,103], it was, however, later successfully applied to other fields and sectors. Kaizen emphasizes reduction of waste and judicious utilization of organizational resources so as to reduce cost. John Maleyeff [104] defined "waste" in the public sector as the "programs or services that do not contribute to the overall well-being of society and therefore constitute a waste of taxpayers' money". The public sector can use the Kaizen principles to reduce waste by getting rid of unnecessary processes and procedures, efficient utilization of human and material resources, objective cost cutting, and ensuring optimum output. Cost cutting is not the only benefit of the Kaizen technique; rather, it helps in the integrated and more synergetic use of assets, material, resources, and staff. Inspired by the private sector, some governmental agencies and local governments have already adopted TQM principles to bring efficiency and effectiveness in their work processes, and a snapshot is provided below.

Kaizen and $C I$ have been successfully instituted in many public sector organizations in the United States, such as the U.S. Department of Defense (DoD), which implemented a framework throughout the department known as Continuous Process Improvement (CPI) and Lean Six Sigma (LSS) [105]. Similarly, the Florida Department of Revenue implemented a customized version in 2003, which they branded as "Six Sigma Light". Through this program, they improved their training program and designed it to be result-oriented, where each trainee identifies a real problem their organization is grappled with, gather data, dig out the root causes, and propose the potential solutions to management [105]. The City of Fort Wayne in the State of Indiana used the Lean technique for a variety of process improvement initiatives [106], such as repairing a pothole in reduced average repair time by getting rid of unnecessary processes and waste. TQM principles are increasingly being used in metropolitan transportation systems such as Madison Metro in Wisconsin, and Ride-On in Maryland. Moreover, the Department of Licensing of Washington State has reduced the drivers' license renewal process time by $50 \%$, by identifying the root causes of delay and improving their processes through Lean Six Sigma. Some respondents have talked about the usefulness as well as challenges in implementing TQM tools in their organizations: 
I'm not aware of how if TQM or Kaizen can help improve work motivation, but I certainly know that it improves the working relationship and we feel like working systematically, as opposed to randomly assigning working to colleagues and teams [S.P-11, 44:21].

It has been two years since we first rolled out improvement program (Kaizen), and it resulted in improving lot more ... work processes, better cost control, better monitoring of progress, less ambiguity and better teamwork [M.P-16, 39:50].

I must say, it wasn't any easy task to do, we tried and failed, and we again tried with certain modifications and this time we succeeded. Based on my experience, it's rather more challenging to master, but once you get hold of it, then it's fun to play and get the work done [D.F-22, 42:13].

\section{Discussion}

Employee motivation and public service motivation has always been an important and critical topic of discussion among scholars in the field of management and public administration. There has been substantial recent scholarship on PSM in wake of new developments in the domain of management and public administration. The shift from new public management [107] to new public governance (NPG) and more recent as public value-based performance governance (PVG) [5]; all have contributed to the discipline of public administration and enticed scholars to stretch their arms in research-based scholarship, making theoretical and empirical contributions to the field.

The existing body of literature on PSM has consistently shown that individuals opting for public service have higher PSM $[30,75,108-111]$ as opposed to their counterparts in private sector. Such individuals are more likely to choose public service as their career as their individual values mesh together well with the mission of the public sector organization. However, this relationship between PSM and the sector choice is not very clear and straightforward, as shown in previous studies [112]. Christensen and Wright posit that their findings do not support this assumption that individuals consciously and purposely select the public sector organizations for the sole purpose of contributing for the public interest, and often it could be utilitarian need that influences individuals' decision to opt for public sector career [112]. Contrary to previous studies $[9,110,111]$ which propose PSM as the primary factor regarding sector choice, our findings reveal a multitude of factors that cause individuals to drift towards the public sector; PSM is one of them, but not the only factor.

Whereas a majority of these studies have empirically proved this claim, Gabris and Simo [58] debunked this narrative of individuals having higher PSM tending to join public service. On the contrary, they maintain that public service motivation does exist, but its effect on employee behavior and attitude towards work is negligible (p. 33). However, our study reveals that the career move to public sector organizations is driven by both the circumstances and opportunities that were available for individuals at the time of entry to public service, as well as the spirit of serving for public good. It could also be triggered by factors such as having grown up and living in a community-like environment, values instilled by the family, volunteering and helping others, seeking a career focusing on people, and longing for intrinsic value from work, etc. Another significant driver to attracting individuals towards public employment has turned out to be seeking a mission-oriented career and meaningful work, which enable individuals to make a tangible contribution in communities. Some interview subjects revealed that they were longing for an organization with the mission and vision of serving and creating a common good for the citizens. Public sector organizations, having the mission of directly and indirectly serving the public, are the right choices for such individuals.

Public sector jobs having stability and long-term job prospects are an ideal choice for individuals looking for a consistent job. Individuals with the intention to serve in a given geographical place are generally look for a stable job, and government jobs having job continuity, decent working hours, and pay and benefits entice them to serve in public sector. Houston [109] posit that women value job security higher than men, and men place less emphasis on job security (p. 768). Our findings are in line with Houston [109] as our female study participants emphasized the value of having a stable job, 
primarily for family reasons. However, job security comes with strings attached with it, as promotion in the public sector is much slower than the corporate sector, given that the government is highly structured and generally has fewer positions available in the hierarchy, especially in local governments. Secondly, employees generally complete their superannuation, primarily for job security and stability. Moreover, given the standardized nature of personnel policies and policy requirements, promotion and upward career moves are quite complicated in public sector, whereas the private sector has more opportunities for lateral and upward moves, and individuals could be placed in different projects.

Since human beings are natural utility maximizers, they look around for opportunities to maximize their benefits and utility. In his seminal work, Dennis Mueller [113] posits that "bureaucrats, like everyone else, can assumed to be selfish utility maximizers" (p. 363). Fulfillment of basic needs is paramount, and some interview respondents linked motivation to Maslow's hierarchy of needs theory [114] and maintained that everyone strives to meet their basic needs first, and if those needs were satisfied then a move might occur for the next level of needs, such as a sense of accomplishment, recognition, feeling pride for serving the public good, and self-actualization, etc. Our findings partly contradict previous studies that argue that increasing extrinsic incentives may undermine intrinsic motivation [41], as intrinsically motivated individuals behave in a certain way without any expectation or greed regarding receiving any monetary benefit. Richard Titmuss [115] asserted that paying money for blood donations may decrease the blood supply as the individuals willing to donate their blood do it with a magnanimous spirit [115]. Many scholars agreed with the notion that public sector employees are altruistic in nature $[42,50,97,116]$ and generally not longing for extrinsic rewards. However, as the respondents contended, every individual strives to fulfill basic and social safety needs, as without having a sound and healthy life, it is second to none to expect individuals would merely be intrinsically motivated without caring about extrinsic needs. Money may not be a big motivator for individuals signing up for public service, however, it would certainly matter if they could not be able to feed their families and fulfill their needs. A respondent put in this way:

Well, first and foremost people need to meet their immediate needs. Like Maslow's hierarchy of needs but I see that day to day in terms of, is your salary enough? [C.L-02, 60:03].

While contrary to the empirical evidence and general perception of the positive outcomes of having higher PSM, recent scholarship has also shown some negative consequences of having higher PSM, which is known as the dark side of PSM $[82,83]$. Some scholars feared that having stronger PSM may potentially induce public servants to behave unethically in the pursuit of fulfilling their duties of public service. Schott and Ritz [83] propositioned that those having greater PSM are more likely to deviate from their public service standards, leading to stress, burnout, and even to the intention of quitting their jobs (p. 6). By contrast, we did not find any negative consequences of higher PSM, rather an increasing commitment and dedication to serve the communities that inspires and bolsters ethical practices. Secondly, local governments, having stringent and transparent accountability systems, are less prone to PSM-induced unethical behavior, since everything is on public record.

Public sector jobs are not necessarily easy, but rather, are highly complex and challenging, and the problems public sector faced are wicked. Our study has revealed an array of factors that inhibited the energy and motivation of employees, and micromanaging and lack of trust lies on the top. Citizens' accusations and bashing of government is another major factor that precludes motivation as one respondent working in the local government maintained that "when a citizen calls me, and either he doesn't know what he's talking about or he's really accusatory or negative about something we are doing, it really pisses me off [R.S-15, 08:21]. Nevertheless, the public sector is not just a job, it is a calling and a meaningful endeavor of serving the citizens and the nation. One City Manager expressed his emotionally charged feelings for public service as:

In public service you will never have a regret, in this worthy endeavor. I just feel lucky and blessed to have spent my time in public service (emphasis added) ... The value of public service, and 
the organization, people get it once they are part of it, it just shows itself, the value shows itself [E.K-05, 00:48].

\section{Implications of the Study for Practice}

The findings of this study will be helpful in better understanding the nuances of the human resource and employee motivation in public sector organizations and myriads of internal organizational and external factors that cause emboldening versus dampening of motivation. The study will also help the policymakers in understanding the career trajectories of public sector employees-the high and low points in their career, and the ways of keeping sustainably high motivation. This study has implications for personnel policymakers as well as human resources professionals dealing with employee-related matters in public sector organizations.

\section{Conclusions}

It goes without saying that employees play a critical role in the success of an organization. Competent and result-oriented employees are an asset of any organization. Responsive, proactive, and agile human resources policies and practices encourage employees to acquire new knowledge, honing their skillsets and fully utilizing their abilities for the realization of organizational goals that directly and indirectly contribute to organizational success. However, one implicit but daunting challenge for managers in both the public and private sector is to keep the employee motivation and morale sustainably high at all times. Many organizations conduct a one-off activity of giving rewards, bonuses, or arrange activities to garner employee motivation. Nevertheless, over time, their motivation starts declining and fading away. In order to keep employee work spirit and motivation high at all times, we suggest TQM principles as an alternative way of stimulating employee motivation on a sustainable and long-term basis. In addition, sustaining PSM also requires a reasonably sophisticated understanding of the role of government, not simply the functions of one's job or organization. This understanding helps to counter the negative influences that oftentimes zap the energy and motivation of public sector employees.

Secondly, the NPM paradigm suggests using the private sector best practices and experiences of quality improvements in the public sector-the customized version of TQM principles-designed to cater to the specific nature of the public sector and local governments as a possible alternative way of bringing efficiency in work processes as well as enhancing employee motivation. Should it be properly planned and executed, TQM improvement drives can greatly help to improve work processes, resulting in better coordination among various organizational units, and this in turn helps in enhancing employee satisfaction and reducing work-related stress as a result of a better working relationship. One of the key challenges of executing TQM or any improvement drive is the resistance from status quo-oriented employees who are unwilling to change and come out of their comfort zones. Therefore, the meaningful, effective, and long-term success of improvement programs requires a change in organizational culture, attitudes, work processes, and embracing change with open arms.

Moreover, good governance is an important pillar of achieving the United Nations' SDGs, as the execution and implementation of the SDG targets and the continuity of the plans and programs of eradicating poverty are largely incumbent upon the public sector officials working in various agencies. Past experiences in many developing countries and, to lesser extent, in developed countries show that many impressive strategic plans and programs could not reach fruition and achieve the desired goals due to shortcomings in implementation and the execution of those programs by the executive branch—governmental agencies and officials responsible for implementing those programs. Hence, good governance-with due attention to human capital and the scaling up of their motivation and morale-is quintessential to meaningfully attaining the SDG targets and delivering timely and quality services to citizens.

In the current era of reduced funding and uncertainty, public sector organizations are grappled with the challenge of keeping their employees engaged, motivated, and retained. This becomes further 
challenging with the populist movements of slashing the perks and benefits of public sector employees and bureaucrats. On the other hand, the private sector is offering lucrative pay packages and fringe benefits that are hard for the public sector to afford.

Moreover, it is becoming increasingly harder to attract and retain the younger people and millennials in the public sector, given their prejudiced perception of the public sector as relatively conservative, bureaucratic, and slow to change, which seems to be fairly untrue in case of local governments. This stereotypical attitude towards government employment impedes the top talent and highly educated younger generation from joining public service. Nevertheless, the kind of edge public sector organizations have (i.e., a mission-oriented and meaningful career), is rarely offered by the private sector. No matter how innovative, effective, and employee-friendly the policies of the private sector, their reason for existence revolves around profit maximization, whereas the public sector essentially has a vision and the mission of extending the public good, and may be the right choice for individuals seeking a meaningful career.

This study employs the grounded theory research design, and the decision to choose GT is based on the vacuum in the existing literature on sustainable motivation and PSM in local governments, as well as methodological rigor and the intensive nature of exploration in GT. This study has policy implications for human resources management in governments, and posit to minimize debilitating factors (discussed in detail in the findings section) that dampen the motivation and morale of local government employees. Moreover, we suggest reinvigorating human resources policies in the local government to address the changing needs and requirements to better serve internal customers (employees) as well as external customers (citizens and community).

Finally, this study endeavored to explicate the underlying factors that cause the motivation and PSM of local government employees to be positively reinforced, or otherwise inhibit the spirit of serving the public. Using the TQM tools of Kaizen and CI to harness sustainable motivation would be a valuable addition to the body of literature on employee motivation and PSM. Future studies could further explore the subtleties of TQM and work motivation and PSM in the public sector by employing both quantitative and qualitative methods, and using a varied range of research designs such as longitudinal, experimental, quasi-experimental, and case studies.

Supplementary Materials: The following are available online at http://www.mdpi.com/2071-1050/11/11/3105/s1, Table S1: Interview Guide.

Author Contributions: Conceptualization, S.H.; methodology, S.H. and M.U.D.; validation, G.B., and G.L.L.; formal analysis, S.H. G.L.L.; investigation, S.H.; data curation, S.H.; writing-original draft preparation, S.H.; writing-review and editing, G.B., G.L.L. and M.U.D.; validation, G.L.L. and M.U.D.; visualization, S.H. and M.U.D.; supervision, G.B. and G.L.L.; project administration, G.B.

Funding: The authorship of this article has been supported by the National Natural Science Foundation of China (NNSF of China No. 71433005).

Acknowledgments: The authors are highly grateful to Douglas F. Morgan, Program Director EMPA and professor Emeritus, and Masami Nishishiba, department Chair MPA program, Portland State University for their invaluable guidance and insights. We also thank Wang Xuejun, Associate Dean, School of Management, Lanzhou University. The authors highly appreciate the helpful comments and guidance of assistant Editor and anonymous Reviewers.

Conflicts of Interest: The authors declare no conflict of interest. 


\section{Appendix A}

Table A1. Participants' Informed Consent; seeking written permission to conduct in-depth interviews.

\begin{tabular}{l} 
The Portland State University \\
Consent to Participate in Research “Harnessing Sustainable Motivation” \\
\hline Introduction \\
You are being asked to participate in a research study that is being undertaken by Professor Douglas Morgan, who is \\
the Principal Investigator and Associate Researchers Dr. Masami Nishishiba and Sajjad Haider, from the \\
Department of Public Administration at Portland State University, Portland, Oregon. This research is studying the \\
change in public service motivation through time. \\
You are being asked to participate in this study because you are an experienced human resource professional in Oregon and \\
respected by your colleagues for your knowledge and concern for public employee motivation. This form will explain the \\
research study, and will also explain the possible risks as well as the possible benefits to you. We encourage you to talk \\
with others before you decide to take part in this research study. If you have any questions, please ask one of the \\
study investigators.
\end{tabular}

\section{What will happen if I decide to participate?}

If you agree to participate, you will be asked to share how your public service motivation has changed over the course of your career and the internal and external factors that might have affected this change. With your permission, we will voice record the interview, solely for transcribing purposes.

How long will I be in this study?

Participation in this study will consist of a one-hour interview.

\section{What are the risks or side effects of being in this study?}

In any study, there are risks of stress, emotional distress, inconvenience, and possible loss of privacy and confidentiality associated with participating in a research study.

In order to reduce the risk of stress, we have carefully reviewed our interview questions to ensure they are as stress-free as possible. We have arranged this interview at a time and place that minimizes inconvenience to you. We will code the information gained from this interview so that the interviewee and the information will be kept confidential.

For more information about risks and discomforts, ask the investigator.

\section{What are the benefits to being in this study?}

We believe that the study results will help public sector human resources professionals understand the dynamics of public service motivation, which in turn can be used to improve public sector human resources practices such as professional development, recruitment, retention, and promotion.

\section{How will my information be kept confidential?}

We will take measures to protect the security of all your personal information, but we cannot guarantee 100\% confidentiality of all study data. We will, however, use pseudonyms in our interview transcript, and keep the list of pseudonyms that corresponds to the identity of the study participants in a password-protected electronic file. Only the research team members will be able to access this list. Your name will not be used in any published reports about this study.

Will I be paid for taking part in this study?

No. You will not be compensated to participate in this study.

\section{Can I stop being in the study once I begin?}

Your participation in this study is completely voluntary. You have the right to choose not to participate or to withdraw your participation at any point in this study without penalty or loss of benefits to which you are otherwise entitled.

\section{Whom can I call with questions or complaints about this study?}

If you have any questions, concern's or complaints at any time about the research study, Sajjad Haider, or his/her associates will be glad to answer them at 971-801-4297.

If you need to contact someone after business hours or on weekends, please call 971-801-4297 and ask for Sajjad Haider.

\footnotetext{
Whom can I call with questions about my rights as a research participant?

If you have questions regarding your rights as a research participant, you may call the PSU Office for Research Integrity at (503) 725-2227 or 1(877) 480-4400. The ORI is the office that supports the PSU Institutional Review Board (IRB). The $I R B$ is a group of people from PSU and the community who provide independent oversight of safety and ethical issues related to research involving human participants. For more information, you may also access the IRB website at https://sites.google.com/a/pdx.edu/research/integrity.
} 
Table A1. Cont.

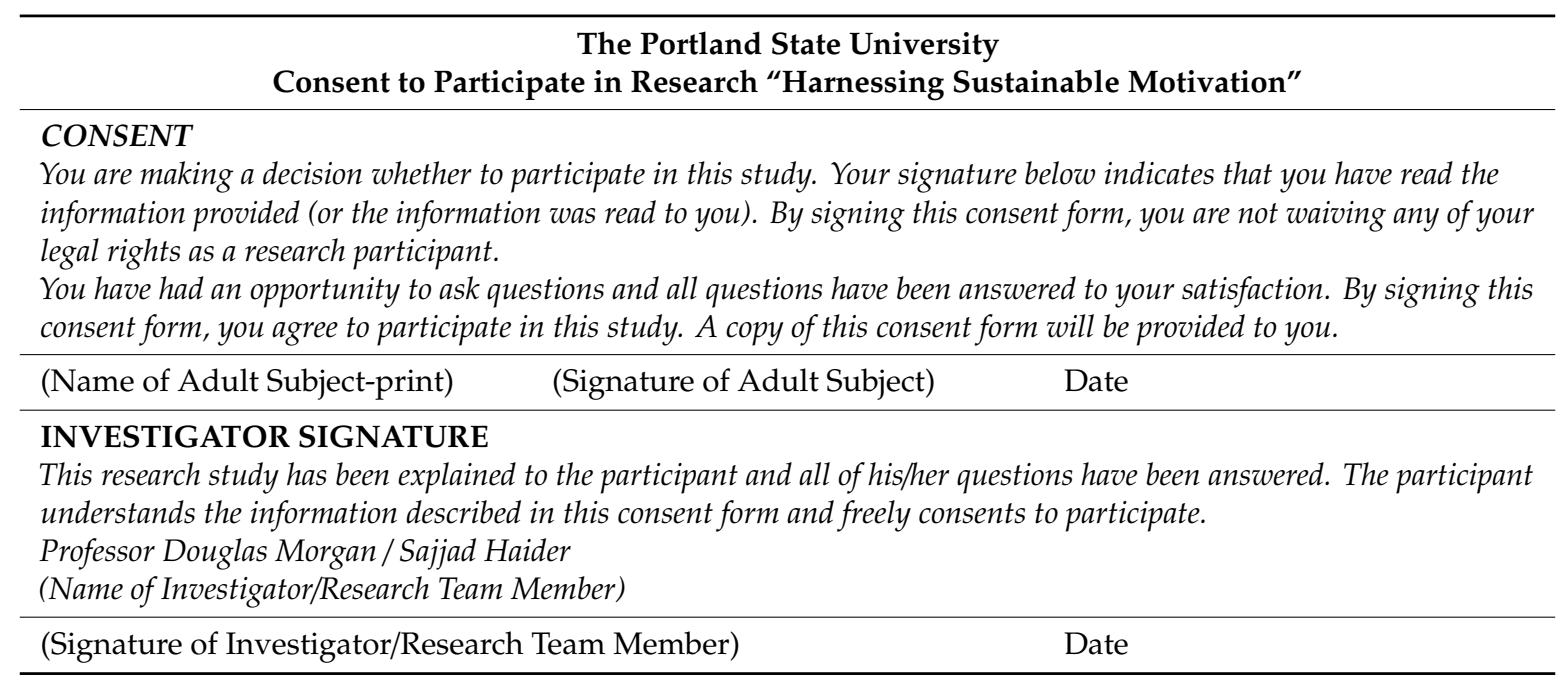

\section{References}

1. World Commission on Environment and Development (WCED). Our Common Future. 1987. Available online: http://www.un-documents.net/our-common-future.pdf (accessed on 23 December 2018).

2. Güney, T. Governance and sustainable development: How effective is governance? J. Int. Trade Econ. Dev. 2017, 26, 316-335. [CrossRef]

3. Petrovsky, N.; Ritz, A. Public service motivation and performance: A critical perspective. In Evidence-Based HRM: A Global Forum for Empirical Scholarship; Emerald Group Publishing Limited: Bingley, UK, 2014; Volume 2, No. 1; pp. 57-79.

4. Bertucci, G.; Ghaus-Pasha, A. Governance for the Millennium Development Goals: Core Issues and Good Practices. In Proceedings of the 7th Global Forum on Reinventing Government, Building Trust in Government, Vienna, Austria, 26-29 June 2007.

5. Bao, G.; Wang, X.; Larsen, G.L.; Morgan, D.F. Beyond new public governance: A value-based global framework for performance management, governance, and leadership. Adm. Soc. 2013, 45, 443-467. [CrossRef]

6. Bhatia, N.; Drew, J. Applying lean production to the public sector. Mckinsey Q. 2006, 3, 97-98.

7. Buchanan, B. Red-tape and the service ethic some unexpected differences between public and private managers. Adm. Soc. 1975, 6, 423-444. [CrossRef]

8. Rainey, H.G. Reward preferences among public and private managers: In search of the service. Am. Rev. Public Adm. 1982, 16, 288-302. [CrossRef]

9. Perry, J.L.; Wise, L.R. The motivational bases of public service. Public Adm. Rev. 1990, 50, 367-373. [CrossRef]

10. Perry, J.L. Measuring public service motivation: An assessment of construct reliability and validity. J. Public Adm. Res. Theory 1996, 6, 5-22. [CrossRef]

11. Naff, K.C.; Crum, J. Working for America: Does public service motivation make a difference? Rev. Public Pers. Adm. 1999, 19, 5-17. [CrossRef]

12. Alonso, P.; Lewis, G.B. Public service motivation and job performance: Evidence from the federal sector. Am. Rev. Pubic Adm. 2001, 31, 363-380. [CrossRef]

13. Brewer, G.A.; Selden, S.C. Whistle blowers in the federal civil service: New evidence of the public service. J. Public Adm. Res. Theory 1998, 8, 413-440. [CrossRef]

14. Brewer, G.A.; Ritz, A.; Vandenabeele, W. Introduction to a symposium on public service motivation: An international sampling of research. Int. J. Public Adm. 2012, 35, 1-4. [CrossRef]

15. Kim, S.; Vandenabeele, W.; Wright, B.E.; Andersen, L.B.; Cerase, F.P.; Christensen, R.B.; Desmarais, C.; Koumenta, M.; Leisink, P.; Liu, B.; et al. Investigating the structure and meaning of public service motivation across populations: Developing an international instrument and addressing issues of measurement variance. J. Public Adm. Res. Theory 2013, 23, 79-102. [CrossRef] 
16. Bright, L. Does person-organization fit mediate the relationship between public service motivation and the job performance of public employees? Rev. Public Pers. Adm. 2007, 27, 361-379. [CrossRef]

17. Bellé, N. Experimental evidence on the relationship between public service motivation and job performance. Public Adm. Rev. 2013, 73, 143-153. [CrossRef]

18. Frank, S.A.; Lewis, G.B. Government employees working hard or hardly working? Am. Rev. Public Adm. 2004, 34, 36-51. [CrossRef]

19. Schneider, B. The people make the place. Pers. Psychol. 1987, 40, 437-453. [CrossRef]

20. Kristof-Brown, A.L.; Zimmerman, R.D.; Johnson, E.C. "Consequences of individuals" fit at work: A meta-analysis of person-job, person organization, person-group, and person-supervisor-fit. Pers. Psychol. 2005, 58, 281-342. [CrossRef]

21. Schott, C.; Steen, T.; Van Kleef, D.D. Reality shock and public service motivation: A longitudinal, qualitative study among Dutch veterinary inspectors. Int. J. Public Adm. 2018, 42, 468-481. [CrossRef]

22. Houston, D.J. Public service motivation: A multivariate test. J. Public Adm. Res. Theory 2000, 10, 713-728. [CrossRef]

23. Kjeldsen, A.M. Sector and occupational differences in public service motivation: A qualitative study. Int. J. Public Adm. 2012, 35, 58-69. [CrossRef]

24. Kjeldsen, A.M.; Jacobsen, C.B. Public service motivation and employment sector: Attraction or socialization? J. Public Adm. Res. Theory 2012, 23, 899-926. [CrossRef]

25. Yung, B. Differential public service motivation among Hong Kong public officials: A qualitative study. Public Pers. Manag. 2014, 43, 415-441. [CrossRef]

26. Ritz, A. Attraction to public policy-making: A qualitative inquiry into improvements in PSM measurement. Public Adm. 2011, 89, 1128-1147. [CrossRef]

27. Carrell, M.R.; Mann, E.E. Defining workforce diversity in public sector organizations. Public Pers. Manag. 1995, 24, 99-111. [CrossRef]

28. Pitts, D.W.; Recascino Wise, L. Workforce diversity in the new millennium: Prospects for research. Rev. Public Pers. Adm. 2010, 30, 44-69. [CrossRef]

29. Riccucci, N. Managing Diversity in Public Sector Workforces: Essentials of Public Policy and Administration Series; Routledge: New York, NY, USA, 2018.

30. Moynihan, D.P.; Pandey, S.K. Finding workable levers over work motivation comparing job satisfaction, job involvement, and organizational commitment. Adm. Soc. 2007, 39, 803-832. [CrossRef]

31. Paarlberg, L.E.; Lavigna, B. Transformational leadership and public service motivation: Driving individual and organizational performance. Public Adm. Rev. 2010, 70, 710-718. [CrossRef]

32. Vogel, D.; Kroll, A. The stability and change of PSM-related values across time: Testing theoretical expectations against panel data. Int. Public Manag. J. 2016, 19, 53-77. [CrossRef]

33. Hughes, E.C. Men and Their Work; Free Press: Glencoe, IL, USA, 1958.

34. Ward, K.D. Cultivating public service motivation through AmeriCorps service: A longitudinal study. Public Adm. Rev. 2014, 74, 114-125. [CrossRef]

35. Bozeman, B. Bureaucracy and Red Tape; Prentice Hall: Upper Saddle River, NJ, USA, 2000.

36. Scott, P.G.; Pandey, S.K. Red tape and public service motivation: Findings from a national survey of managers in state health and human services agencies. Rev. Public Pers. Adm. 2005, 25, 155-180. [CrossRef]

37. Guyot, J.F. Government bureaucrats are different. Public Adm. Rev. 1962, 22, 195-202. [CrossRef]

38. Kilpatrick, F.; Cummings, M.C.; Jennings, M.K. The Image of the Federal Service; Brookings: Washington, DC, USA, 1964.

39. Jensen, U.T.; Bro, L.L. How transformational leadership supports intrinsic motivation and public service motivation: The mediating role of basic need satisfaction. Am. Rev. Public Adm. 2018, 48, 535-549. [CrossRef]

40. Crewson, P.E. Public service motivation: Building empirical evidence of incidence and effect. J. Public Adm. Res. Theory 1997, 7, 499-518. [CrossRef]

41. Georgellis, Y.; Iossa, E.; Tabvuma, V. Crowding out intrinsic motivation in the public sector. J. Public Adm. Res. Theory 2010, 21, 473-493. [CrossRef]

42. Kim, S. Public service motivation and organizational citizenship behavior in Korea. Int. J. Manpow. 2006, 27, 722-740. [CrossRef]

43. Dur, R.; Zoutenbier, R. Working for a good cause. Public Adm. Rev. 2014, 74, 144-155. [CrossRef] 
44. Ryan, R.M.; Deci, E.L. Intrinsic and extrinsic motivations: Classic definitions and new directions. Contemp. Educ. Psychol. 2000, 25, 54-67. [CrossRef]

45. Bright, L. Why do public employees desire intrinsic nonmonetary opportunities? Public Pers. Manag. 2009, 38, 15-37. [CrossRef]

46. Oberfield, Z. Motivation, change and stability: Finding from an urban police department. Am. Rev. Public Adm. 2014, 44, 210-229. [CrossRef]

47. United Nations Development Programme-Global Center for Public Service Excellence (UNDP-GCPSE, 2014). Motivation of Public Service Officials: Insights for Practitioners. Available online: https:/www.undp.org/content/dam/undp/library/capacity-development/English/Singapore\% 20Centre/GCPSE_PSM_Summary.pdf (accessed on 3 March 2019).

48. Bozeman, B.; Su, X. Public service motivation concepts and theory: A critique. Public Adm. Rev. 2015, 75, 700-710. [CrossRef]

49. Weske, U.; Schott, C. What motivates different groups of public employees working for Dutch municipalities? Combining autonomous and controlled types of motivation. Rev. Public Pers. Adm. 2018, 38, 415-430. [CrossRef]

50. Houston, D.J. "Walking the walk" of public service motivation: Public employees and charitable gifts of time, blood, and money. J. Public Adm. Res. Theory 2006, 16, 67-86. [CrossRef]

51. Deci, E.L.; Ryan, R.M. Intrinsic Motivation and Self-Determination in Human Behavior; Plenum: New York, NY, USA, 1985.

52. Gagné, M.; Deci, E.L. Self-determination theory and work motivation. J. Organ. Behav. 2005, 26, 331-362. [CrossRef]

53. Bakker, A.B. A job demands-Resources approach to public service motivation. Public Adm. Rev. 2015, 75, 723-732. [CrossRef]

54. Brænder, M.; Andersen, L.B. Does deployment to war affect public service motivation? A panel study of soldiers before and after their service in Afghanistan. Public Adm. Rev. 2013, 73, 466-477. [CrossRef]

55. Lee, C.; Kim, S. Making the quality of government better: The possibility of public service motivation (PSM) change. Int. Rev. Public Adm. 2014, 19, 107-125. [CrossRef]

56. Wright, B.E.; Grant, A.M. Unanswered questions about public service motivation: Designing research to address key issues of emergence and effects. Public Adm. Rev. 2010, 70, 691-700. [CrossRef]

57. Christensen, R.K.; Paarlberg, L.; Perry, J.L. Public service motivation research: Lessons for practice. Public Adm. Rev. 2017, 77, 529-542. [CrossRef]

58. Gabris, G.T.; Simo, G. Public sector motivation as an independent variable affecting career decisions. Public Pers. Manag. 1995, 24, 33-51. [CrossRef]

59. Beer, M. Why total quality management programs do not persist: The role of management quality and implications for leading a TQM transformation. Decis. Sci. 2003, 34, 623-642. [CrossRef]

60. Panagiotis, M.; Alexandros, S.; George, P. Organizational culture and motivation in the public sector. The case of the city of Zografou. Procedia Econ. Financ. 2014, 14, 415-424. [CrossRef]

61. Bergquist, B.; Fredriksson, M.; Svensson, M. TQM: Terrific quality marvel or tragic quality malpractice? TQM Mag. 2005, 17, 309-321. [CrossRef]

62. Denhardt, R.B.; Denhardt, J.V. The new public service: Serving rather than steering. Public Adm. Rev. 2000, 60, 549-559. [CrossRef]

63. Ferlie, E. Complex organizations and contemporary public sector organizations. Int. Public Manag. J. 2007, 10, 153-165. [CrossRef]

64. Head, B.W. How can the public sector resolve complex issues? Strategies for steering, administering and coping. Asia-Pac. J. Bus. Adm. 2010, 2, 8-16. [CrossRef]

65. Hasenfeld, Y. Human Services as Complex Organizations; Sage Publications: Thousand Oaks, CA, USA, 2009.

66. Osborne, S.P. (Ed.) The New Public Governance: Emerging Perspectives on the Theory and Practice of Public Governance; Routledge: London, UK, 2010.

67. Gould-Williams, J. The importance of HR practices and workplace trust in achieving superior performance: A study of public-sector organizations. Int. J. Hum. Resour. Manag. 2003, 14, 28-54. [CrossRef]

68. Glaser, B.G.; Strauss, A.L. The Discovery of Grounded Theory: Strategies for Qualitative Research; Aldine: Chicago, IL, USA, 1967. 
69. Strauss, A. and Corbin, J. Basics of Qualitative Research: Techniques and Procedures for Developing Grounded Theory; Sage: Thousand Oaks, CA, USA, 1998.

70. Charmaz, K. Constructing Grounded Theory: A Practical Guide through Qualitative Analysis; Sage Publications: London, UK, 2006.

71. Charmaz, K. Constructing Grounded Theory, 3rd ed.; Sage: Thousand Oaks, CA, USA, 2014.

72. Tummers, L.; Karsten, N. Reflecting on the role of literature in qualitative public administration research: Learning from grounded theory. Adm. Soc. 2012, 44, 64-86. [CrossRef]

73. Brewer, G.A.; Selden, S.C.; Facer II, R.L. Individual conceptions of public service motivation. Public Adm. Rev. 2000, 60, 254-264. [CrossRef]

74. Staats, E.B. Public service and the public interest. Public Adm. Rev. 1988, 48, 601-605. [CrossRef]

75. Taylor, J. Organizational influences, public service motivation and work outcomes: An Australian study. Int. Public Manag. J. 2008, 11, 67-88. [CrossRef]

76. Jacobsen, C.B.; Hvitved, J.; Andersen, L.B. Command and motivation: How the perception of external interventions relates to intrinsic motivation and public service motivation. Public Adm. 2013, 92, 790-806. [CrossRef]

77. Andersen, L.B.; Bjørnholt, B.; Bro, L.L.; Holm-Petersen, C. Leadership and motivation: A qualitative study of transformational leadership and public service motivation. Int. Rev. Adm. Sci. 2018, 84, 675-691. [CrossRef]

78. Perry, J.L.; Vandenabeele, W. Public service motivation research: Achievements, challenges, and future directions. Public Adm. Rev. 2015, 75, 692-699. [CrossRef]

79. Pedersen, M.J. Activating the forces of public service motivation: Evidence from a low-intensity randomized survey experiment. Public Adm. Rev. 2015, 75, 734-746. [CrossRef]

80. Stritch, J.M.; Christensen, R.K. Going green in public organizations: Linking organizational commitment and public service motives to public employees' workplace eco-initiatives. Am. Rev. Public Adm. 2016, 46, 337-355. [CrossRef]

81. Kim, S.H.; Kim, S. Social desirability bias in measuring public service motivation. Int. Public Manag. J. 2016, 19, 293-319. [CrossRef]

82. Jensen, U.T.; Andersen, L.B.; Holten, A.L. Explaining a dark side: Public service motivation, presenteeism, and absenteeism. Rev. Public Pers. Adm. 2017, 1-24. [CrossRef]

83. Schott, C.; Ritz, A. The dark sides of public service motivation: A multi-level theoretical framework. Perspect. Public Manag. Govern. 2017, 1, 29-42. [CrossRef]

84. United Nations Academic Impact. Sustainability. 2019. Available online: https://academicimpact.un.org/ content/sustainability (accessed on 7 January 2019).

85. Chams, N.; García-Blandón, J. On the importance of sustainable human resource management for the adoption of sustainable development goals. Resour. Conserv. Recycl. 2019, 141, 109-122. [CrossRef]

86. UNDP-Global Centre for Public Service Excellence (UNDP-GCPSE). Public Service Motivation and the SDGs: An Unacknowledged Crisis? Notes on Public Service Excellence \# 13; United Nations Development Programme (UNDP): Singapore, 2017; Available online: http://www.undp.org/publicservice (accessed on 23 October 2018).

87. Bryman, A.; Bell, E. Breaking down the quantitative/qualitative divide. In Business Research Methods; Oxford University Press: Oxford, UK, 2003; pp. 465-478.

88. Locke, K. Grounded Theory in Management Research; SAGE Publications Ltd.: London, UK, 2001.

89. Patton, M.Q. How to Use Qualitative Methods in Evaluation; Sage: Newbury, CA, USA, 1987.

90. Oktay, J.S. Grounded Theory; Oxford University Press: New York, NY, USA, 2012.

91. Wright, B.E. Methodological challenges associated with public service motivation research. In Motivation in Public Management. The Call of Public Service; Perry, J.L., Hondeghem, A., Eds.; Oxford University Press: New York, NY, USA, 2008; pp. 80-98.

92. Punch, K.F. Introduction to Social Research: Quantitative and Qualitative Approaches; Sage: London, UK, 1998.

93. Hair, J.F.; Celsi, M.; Ortinau, D.J.; Bush, R.P. Essentials of Marketing Research; McGraw-Hill Irwin: New Yok, NY, USA, 2008.

94. Nabatchi, T.; Amsler, L.B. Direct public engagement in local government. Am. Rev. Public Adm. 2014, 44, 63S-88S. [CrossRef]

95. Nishishiba, M. Local government diversity initiatives in Oregon: An exploratory study. State Local Gov. Rev. 2012, 44, 55-66. [CrossRef] 
96. U.S. Census Bureau. Employment Summary Report. 2012. Available online: https://www2.census.gov/govs/ apes/2012_summary_report.pdf (accessed on 20 March 2018).

97. Perry, J.L. Bringing society in: Towards a theory of public service motivation. J. Public Adm. Res. Theory 2000, 10, 471-488. [CrossRef]

98. Andrle, S.J. Total Quality Management in Public Transportation. Research Results Digest. Number 3. 1994. Available online: http://onlinepubs.trb.org/onlinepubs/tcrp/tcrp_rrd_03.pdf (accessed on 22 February 2019).

99. Suarez-Barraza, M.F.; Smith, T.; Dahlgaard-Park, S. Lean-kaizen public service: An empirical approach in Spanish local governments. TQM J. 2009, 21, 143-167. [CrossRef]

100. Yasin, M.M.; Wafa, M.A.; Small, M.H. Just-in-time implementation in the public sector: An empirical examination. Int. J. Oper. Prod. Manag. 2001, 21, 1195-1204. [CrossRef]

101. Hasenjager, J. Lean government (is not an oxymoron): A Connecticut agency in efficiency's court. Ind. Eng. 2006, 38, 43-48.

102. Krings, D.; Levine, D.; Wall, T. The use of lean in local government. Public Manag. 2006, 88, 12-17.

103. Imai, M. Kaizen - The Key to Japan's Competitive Success; Random House: New York, NY, USA, 1986.

104. Maleyeff, J. Analysis of service processes characteristics across a range of enterprises. J. Serv. Sci. Manag. 2009, 2, 29. [CrossRef]

105. Maleyeff, J. Improving service delivery in government with lean six sigma. In Strategy and Transformation Series; IBM Center for Business of Government, 2007. Available online: http://asq.org/gov/improving-servicedelivery-in-in-government-with-lean-six-sigma.pdf (accessed on 7 January 2019).

106. Furterer, S.; Elshennawy, A.K. Implementation of TQM and lean Six Sigma tools in local government: A framework and a case study. Total Qual. Manag. Bus. Excell. 2005, 16, 1179-1191. [CrossRef]

107. Osborne, D.; Gaebler, T. Reinventing Government: How the Entrepreneurial Spirit Is Transforming in the Public Sector; Penguin Press: New York, NY, USA, 1992.

108. Buelens, M.; Van den Broeck, H. An analysis of differences in work motivation between public and private sector organizations. Public Adm. Rev. 2007, 67, 65-74. [CrossRef]

109. Houston, D.J. Implications of occupational locus and focus for public service motivation: Attitudes toward work motives across nations. Public Adm. Rev. 2011, 71, 761-771. [CrossRef]

110. Leisink, P.; Steijn, B. Public service motivation and job performance of public sector employees in the Netherlands. Int. Rev. Adm. Sci. 2009, 75, 35-52. [CrossRef]

111. Vandenabeele, W. Government calling: Public service motivation as an element in selecting government as an employer of choice. Public Adm. 2008, 86, 1089-1105. [CrossRef]

112. Christensen, R.K.; Wright, B.E. The effects of public service motivation on job choice decisions: Disentangling the contributions of person-organization fit and person-job fit. J. Public Adm. Res. Theory 2011, 21, 723-743. [CrossRef]

113. Mueller, D.C. Public Choice III; Cambridge University Press: New York, NY, USA, 2003.

114. Maslow, A. A theory of human motivation. Psychol. Rev. 1943, 50, 370-396. [CrossRef]

115. Titmuss, R.M. The Gift Relationship. From Human Blood to Social Policy; Oakley, A., Ashton, J., Eds.; New Press: New York, NY, USA, 1970.

116. Vandenabeele, W. Towards a public administration theory of public service motivation: An institutional approach. Public Manag. Rev. 2007, 9, 545-556. [CrossRef]

(C) 2019 by the authors. Licensee MDPI, Basel, Switzerland. This article is an open access article distributed under the terms and conditions of the Creative Commons Attribution (CC BY) license (http://creativecommons.org/licenses/by/4.0/). 